\title{
Dez anos de SINAES: um mapeamento de teses e dissertações defendidas no período 2004 - 2014
}

\author{
Paulo Roberto Teixeira Junior \\ Monica Piccione Gomes Rios
}

RESUMO: O Sistema Nacional de Avaliação da Educação Superior (SINAES) foi instituído em 2004, no lugar do Exame Nacional de Cursos (ENC) conhecido, à época, como "Provão". Em dez anos de vigência, o SINAES passou por várias mudanças e tornou-se objeto de pesquisa de inúmeros programas de pósgraduação no país. O presente estudo é um inventário das teses e dissertações sobre o SINAES defendidas no período entre 2004 e 2014. Utilizamo-nos da Biblioteca Digital de Teses e Dissertações (BDTD) e do Banco de Teses e Dissertações da CAPES. Resultados demonstram que foram produzidas, no período, 101 obras, sendo a maioria sobre o eixo 'avaliação institucional' e a minoria sobre 'avaliação de curso'. Universidade de Brasília é a instituição que mais produziu sobre o SINAES, sendo o professor José Vieira o que orientou o maior número de pesquisas, seguido da Universidade Federal do Ceará e professor Wagner Andriola, respectivamente. Por fim, tal mapeamento permite uma visão panorâmica do que se produziu sobre o SINAES na primeira década de sua existência: tendências, recorrências, silêncios, lugares e pessoas envolvidas com essa temática no país.

Palavras-chaves: SINAES. Educação superior. Avaliação.

Ten years of sinaes: a bibliographic mapping of master and doctoral thesis' produced from 2004 to 2014

ABSTRACT: The National System of Evaluation of Higher Education (SINAES) was instituted in 2004, instead of the National Exam of Courses (ENC) known at the time as "Provão". In ten years of existence, the SINAES underwent several changes and became the object of research of numerous graduate programs in the country. The present study is an inventory of theses and dissertations on SINAES defended in the period between 2004 and 2014. We use the Digital Library of Theses and Dissertations (BDTD) and the Bank of Theses and Dissertations of CAPES. Results show that 101 works were produced in the period, most of them being on the 'institutional evaluation' axis and the minority on 'course evaluation'. Brasilia University is the institution that most produced on SINAES, with Professor José Vieira leading the largest number of researches, followed by the Federal University of Ceará and professor Wagner Andriola, respectively. Finally, such mapping allows a panoramic view of what has been produced about SINAES in the first decade of its existence: trends, recurrences, silences, places and people involved with this issue in the country.

Key-words: SINAES. Higher education. Assessment. 


\section{Introdução}

No nível de graduação, quando pensamos em processos sistemáticos de avaliação das instituições de ensino superior (IES), as primeiras iniciativas ocorreram em 1993, com o Programa de Avaliação Institucional das Universidades Brasileiras (PAIUB). Em seguida, o Exame Nacional de Cursos (ENC), que vigorou de 1995 a 2003 e, por fim, o Sistema Nacional de Avaliação da Educação Superior (SINAES) em 2004, que vigora até os dias atuais.

É possível também analisarmos a historiografia da avaliação da educação superior de maneira mais abrangente e considerarmos as iniciativas empreendidas antes de 1993: Plano Atcon em 1966, Comissão Meira Mattos em 1968, Grupo de Trabalho de julho de 1968, Programa de Avaliação da Reforma Universitária (PARU) em 1983, Comissão Nacional para Reformulação do Ensino Superior (CNRES) em 1985 e o Grupo Executivo para Reformulação do Ensino Superior (GERES) em 1986.

Tais iniciativas antes do PAIUB não se caracterizaram, propriamente, como processos avaliativos contínuos, de medição, comparação e acompanhamento, como ocorrera a partir do PAIUB. O caráter daquelas ações era eventual e fotográfico, ou seja, diagnosticar a situação do ensino universitário no país, naquele dado momento, sem uma preocupação de acompanhamento longitudinal.

As medidas de avaliação da década de 1960 - Plano Atcon, Comissão Meira Mattos e Grupo de Trabalho de Julho de 1968 - tiveram como finalidade última diagnosticar e preparar o cenário para a Reforma Universitária de 1968 (Lei no 5.540 de 28 de novembro de 1968). Tal reforma previa a modernização administrativa e expansão da rede de universidades federais, bem como a criação de condições jurídico-institucionais que facilitasse a expansão da emergente rede de escolas privadas. A Reforma, ainda que não tornasse isso explícito, também tinha objetivos no campo pedagógico-ideológico. A extinção das cátedras, a criação do sistema de créditos e semestres, por exemplo, diluía o poder e agremiação de professores e alunos, afinal, eram tempos de regime ditatorial militar, e a universidade era um dos redutos de resistência que precisava ser combatido e vigiado.

Após a instauração da Reforma Universitária, não houve novas iniciativas de avaliação durante quinze anos. Somente em 1983, já em clima de redemocratização do país, novas comissões são instituídas para fazer uma espécie de balanço da Reforma e, certo modo, já emoldurar o cenário para a instauração de um novo modelo de avaliação da educação superior, calcado na autonomia das instituições, e não na sua opressão, como vinha ocorrendo até então. 
Assim, as avaliações anteriores ao PAIUB são uma espécie de 'pré-história' da avaliação da educação superior, pois emanavam estritamente do governo, sem diálogo com as entidades docentes, tampouco estudantis. O objetivo era o controle administrativo e manutenção da 'ordem e progresso', tal como preconizado pelos países sob comando ideológico dos Estados Unidos pós-Segunda Guerra Mundial.

O PAIUB foi a primeira tentativa de se avaliar as IES por meio de um sistema, de fato, tendo como epicentro do processo a autoavaliação institucional. O programa tinha como alvo primário a graduação, em que os problemas eram mais urgentes e necessitava de uma ação direta do Estado, mas poderia englobar também a pós-graduação e a extensão. A adesão ao programa era voluntária; cada IES definia se participava ou não e qual de suas esferas de atuação - graduação ou pós-graduação ou extensão - se submeteria ao processo.

O PAIUB não tinha intenções de ranquear instituições. O objetivo era diagnosticar o funcionamento dos cursos e devolver essas informações à própria instituição, que a partir delas tomaria as ações corretivas necessárias. Porém, tal como acontece com várias políticas públicas brasileiras, o PAIUB definhou com a emergência de um novo governo, que trouxe uma nova proposta para a avaliação da educação superior: o governo Fernando Henrique Cardoso e o Exame Nacional de Cursos (ENC), conhecido como "Provão".

Paulo Renato Souza é nomeado Ministro da Educação. Um novo modelo avaliativo é concebido no lugar do PAIUB: ao invés de avaliações institucionais in locu, aplica-se um exame aos estudantes últimos anistas para aferir conhecimentos e habilidades. Comparecer ao exame era obrigatório para obtenção do diploma, ainda que sua realização efetiva não o fosse. Ou seja, houve muitos boicotes; os alunos compareciam ao exame, preenchiam o formulário básico com dados pessoais para constatação de presença, mas deixavam a prova em branco.

Havia expectativa da sociedade em relação à divulgação dos resultados, ao estilo 'melhores versus piores'. De uma forma ou de outra, isso ocorreu, em meio a muitas resistências das IES públicas, que sempre se mostraram contrárias a exposições que pudessem servir para algum tipo de ranqueamento. Os oito anos de Provão se desenrolaram em meio a essas tensões, instigando muita polêmica e movimentações por parte das IES, públicas e privadas. Com intenções mercadológicas ou não, o fato é que o Provão forçou escolas a saírem do lugar comum e a repensarem seus processos de ensino-aprendizagem. Ou, pelo menos, a repensarem propostas alternativas de avaliação. O que não se concebia mais, de fato, era a não-avaliação. Isto é, urgia a necessidade de se criar formas de tornar público o que as universidades faziam. O ENC perdurou até 2003, quando então surgiu um novo modelo avaliativo, a reboque de um novo governo que assumira: o SINAES no governo Luís Inácio Lula da Silva. 
Neste artigo, traçamos um breve histórico do SINAES, apresentando em seguida um levantamento feito por nós junto à Biblioteca Digital de Teses e Dissertações (BDTD) e Banco de Teses e Dissertações da Coordenação de Aperfeiçoamento de Pessoal de Nível Superior (CAPES) de trabalhos cujo o SINAES tenha sido objeto de pesquisa no período de 2004 a 2014. Tal mapeamento nos permite visualizar temáticas, lugares e pessoas debruçadas sobre o estudo dessa política pública no Brasil e, assim, estabelecer conexões, perceber lacunas e pensar novos projetos de pesquisa que contribuam com a compreensão e melhoria do SINAES.

\section{O SINAES: da concepção, à implementação}

Por meio da Lei $\mathrm{n}^{\circ} 10.861$, de 14 de abril de 2004, o SINAES é instituído no país, constituído por três componentes-eixos, que são suas unidades de análise, do geral para o específico: (i) avaliação da instituição; (ii) avaliação do curso e (iii) avaliação do estudante.

A avaliação da instituição ocorre por duas vias: a autoavaliação e a avaliação externa, realizada por uma comissão de especialistas designada pelo MEC. A lei do SINAES, em seu do artigo 11, obriga todas as instituições de ensino superior - públicas e privadas - a constituir uma Comissão Própria de Avaliação (CPA), que será responsável pela coordenação dos processos de avaliação interna da IES. A CPA deve ser composta, equitativamente, por membros de todos os segmentos da comunidade interna: docentes, discentes, funcionários técnico-administrativos e membros da sociedade civil organizada. O texto da Lei deixa claro que é proibido compor uma CPA que privilegie a presença de um segmento em detrimento de outro.

A função precípua da CPA é organizar e coordenar a autoavaliação, considerada o epicentro do SINAES. Os demais processos - avaliação externa, avaliação dos cursos e avaliação dos estudantes - ou partirão da autoavaliação ou a ela convergirão. Talvez seja este o elemento mais marcante que o SINAES, em sua concepção original, herdou do PAIUB: o protagonismo da autovaliação.

\footnotetext{
O processo de auto-avaliação é o primeiro passo que compõe a avaliação interna, sendo que, na sua sequência, é realizada uma avaliação externa por professores de outras IES do país, especialmente selecionados e capacitados para tal função. Esta fase é desenvolvida in loco por meio de visitas que têm como objetivo verificar informações disponibilizadas anteriormente, conhecer a IES, mas, sobretudo, auxiliar na construção de ações que possam vir a beneficiar o desenvolvimento do ensino oferecido pela IES (POLIDORI et al., 2006, p. 431).
}

Em 2004, a Comissão Nacional de Avaliação da Educação Superior (CONAES) publicou o documento "Orientações gerais para o roteiro da autoavaliação das instituições", 
sugerindo assuntos e caminhos para as CPA realizarem a autoavaliação. Dentre essas sugestões, a de organizar o processo em torno das dez dimensões do SINAES, apresentadas no artigo $3^{\circ}$ da lei do SINAES: i) missão e plano de desenvolvimento institucional; ii) políticas de ensino, pesquisa, pós-graduação e extensão; iii) responsabilidade social; iv) comunicação com a sociedade; v) políticas de pessoal; vi) organização e gestão; vii) infraestrutura física, biblioteca, recursos de informação e comunicação; viii) planejamento, avaliação e meta-avaliação; ix) política de atendimento aos estudantes e egressos e x) sustentabilidade financeira.

O manual do CONAES sugere pautar o processo sobre tais dimensões, mas também reforça que a IES tem autonomia para seguir ou não esses parâmetros, criar novos, adaptá-los à realidade institucional. Enfim, o objetivo da autoavaliação é fomentar na comunidade interna uma cultura de permanente reflexão sobre si mesma, sobre seus processos internos, seu papel e sua responsabilidade perante a sociedade. O documento produzido pela CPA nessa fase será analisado pela comissão de especialistas que fará a avaliação externa - esta sim pautada sobremaneira nas dez dimensões - para confrontar, somar e balizar olhares de diferentes perspectivas. As informações produzidas tanto pela CPA como pela comissão externa são recebidas e analisadas pela CONAES, que emite um parecer final e encaminha à IES. Cada uma das dimensões, bem como o conjunto das dez dimensões são pontuadas numa escala com cinco níveis.

O segundo componente - avaliação do curso - é realizado também por uma comissão externa, porém diferente da comissão que avaliou a instituição. Nesta, a equipe é formada, majoritariamente, por especialistas naquela área específica de conhecimento cujo curso está sendo avaliado. Majoritariamente, mas não exclusivamente. Na comissão também há um membro da avaliação anterior - avaliação institucional - cujo papel é contribuir com a composição dos dados produzidos e promover conexões entre a avaliação institucional e a avaliação do curso.

A avaliação de curso também é pautada em dimensões extraídas da Lei 10.861, em seu art. $4^{\circ}$ : i) organização didático-pedagógica; ii) perfil do corpo docente, discente e técnicoadministrativo; iii) instalações físicas. E cada uma dessas dimensões são avaliadas por meio de uma dada quantidade de indicadores, havendo pesos diferentes para cada dimensão e até mesmo para cada indicador. 


\section{Figura 1 - Estrutura funcional do SINAES}

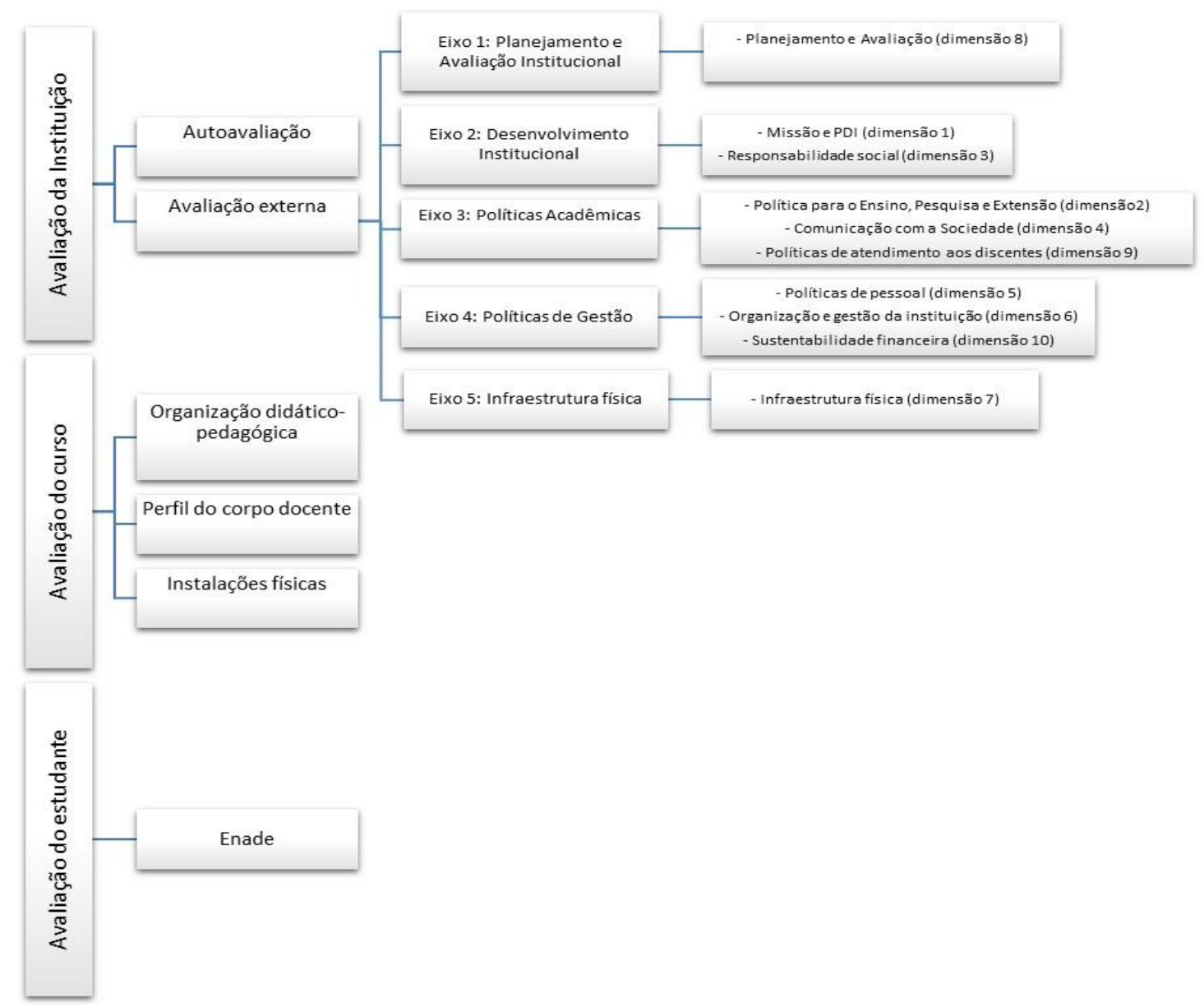

Fonte: elaboração própria

O conjunto de dados produzido pelo sistema seria recebido e processado por uma comissão - a Comissão Nacional de Avaliação da Educação Superior (CONAES) - uma autarquia federal cujos membros seriam designados pela presidência da república. No projeto original, o CONAES não teria funções executiva nem regulatória, mas sim de coordenação do processo. A operacionalização, propriamente, ficaria por conta do Instituto Nacional de Estudos e Pesquisas Educacionais “Anísio Teixeira” (Inep) e da Secretaria de Educação Superior (SESu) ligados diretamente ao MEC.

O produto final de todo o processo avaliativo não seria um ranqueamento, mas sim relatórios descritivos das instituições, que subsidiariam tomadas de decisão dos gestores educacionais, públicos e privados. No limite, o objetivo do sistema era fomentar uma cultura permanente de avaliação (e autovaliação) no interior das instituições, procurando desfazer o estigma de auditoria e punição. Mas, como afirma Barreyro (2004, p. 44) "esta visão autoreguladora, talvez um pouco idealista para quem conhece a realidade de algumas 
instituições privadas, pôde ser um dos motivos da disputa". E, de fato, o foi, como se verá mais adiante.

No fim do primeiro mandato do presidente Lula, tendo à frente do MEC Fernando Haddad, ocorreu a promulgação do Decreto $\mathrm{n}^{\circ} 5.773$ de 9 de maio de 2006, conhecido como decreto-ponte, que definia as funções de regulação, supervisão e avaliação dos cursos superiores, reforçando assim o papel fiscalizador do Estado. Segundo Barreyro e Rothen (2006, p. 66) "o exercício da função de supervisão do sistema centrou-se na utilização dos resultados do ENADE como balizador para a realização de visitas in loco por especialistas, enviados pelo MEC para verificação".

No início de 2007, Fernando Haddad visitou a Ordem dos Advogados do Brasil (OAB) e anunciou novos critérios para a abertura de cursos de Direito e Medicina (Portal MEC, 2007). Houve outras aproximações e impasses entre MEC e OAB. Uma delas ocorreu em julho de 2007, quando o MEC autorizou a abertura de vinte novos cursos de Direito, sendo que a OAB deu parecer favorável a apenas um. O MEC declarou que não abriria mão de sua competência de regular e decidir nesta seara. Além disso, outra ação polêmica foi a comparação entre o exame da OAB e o ENADE. Segundo Rothen \& Barreiro (2011, p. 29) "pela análise divulgada, dos cursos que obtiveram nota 1 ou 2 no ENADE, só $10 \%$ dos seus alunos que fizeram o exame da Ordem foram aprovados".

Em que pese a gama de críticas que esta suposta equivalência entre o exame da Ordem e o ENADE sofreu, o que se descortinava era um fato novo e marcante no segundo governo Lula: o ENADE, tal como o Provão, assumiria o protagonismo do sistema e passaria a funcionar como uma espécie de índice-base das principais decisões do MEC perante as IES. Conforme Dias Sobrinho (2008, p. 821):

\footnotetext{
O INEP destituiu a avaliação institucional e erigiu o ENADE - agora um exame estático e somativo, não mais dinâmico e formativo - como centro de sua avaliação, atribuindo-lhe um peso muito maior do que ele tinha antes. Isso não é uma simples mudança de metodologia. É, sim, uma mudança radical do paradigma de avaliação: da produção de significados e reflexão sobre os valores do conhecimento e da formação, para o controle, a seleção, a classificação em escalas numéricas.
}

Em agosto de 2008, por meio da Portaria Normativa $n^{\circ} 4$, o governo cria o Conceito Preliminar de Cursos (CPC) que seria composto pelos resultados do ENADE, dados do Censo da Educação Superior (CESu) e outros insumos institucionais que teriam maior impacto na nota do ENADE, qual seja, equipamentos disponíveis para as aulas, planos de ensino, nível de qualificação e dedicação dos professores aos cursos. 
Um fator que recebeu críticos neste novo modelo é que a avaliação dos equipamentos e planos de ensino seria realizada pelos alunos, e não por uma comissão avaliadora externa. $\mathrm{O}$ CPC passou a definir, então, quem receberia ou não a comissão de especialistas in loco. Obtendo o conceito 3 ou mais, a IES estaria isenta de receber a comissão. De cerca de 3000 visitas previstas, com a instituição do CPC, 1800 passariam a receber as comissões do MEC. Isso soava como uma espécie de aligeiramento do processo de reconhecimento e um "nivelamento por baixo" das instituições. De acordo com Reynaldo Fernandes, presidente do INEP nessa ocasião, os índices não tinham propriamente a função de dizer quem seriam os melhores, mas sim “a identificação de cursos que não atendem a um nível mínimo de qualidade" (FERNANDES et al., 2009, p. 9).

Uma outra crítica que o CPC sofreu é sobre sua legitimidade jurídica. Como escreve Barreyro e Rothen "A instituição do CPC foi realizada por portaria, como se fosse apenas uma questão operacional decorrente da implementação do SINAES, e não uma mudança central que retoma velhas concepções e discussões sobre os modelos de avaliação da educação superior no país" (2014, p. 70).

Ou seja, uma portaria, que do ponto de vista jurídico se subordina à Lei da qual se trata, promoveu uma mudança substancial no SINAES, afinal de contas, o parágrafo $1^{\circ}$ do artigo $4^{\circ}$ da Lei do SINAES diz que as visitas de especialistas para avaliação de cursos são obrigatórias. No entanto, a portaria de 2008 define que tais visitam só ocorreriam para cursos e instituições com CPC 1 e 2.

Apenas um mês depois, em setembro de 2008, por meio da Portaria Normativa $\mathrm{n}^{\circ} 12$, mais um índice é criado: Índice Geral de Cursos (IGC), que se torna o último estágio do processo de conversão do SINAES em um conjunto de índices ranqueáveis.

O IGC é calculado anualmente, a partir da: (i) média ponderada ${ }^{1}$ dos 3 últimos $\quad$ CPC dos cursos avaliados; (ii) média das notas dos programas de pós-graduação stricto senso ponderada pelo número de alunos nestes programas e convertida para uma escala compatível aos cursos de graduação ${ }^{2}$ e a (iii) distribuição dos estudantes entre os diferentes níveis: graduação ou pós-graduação, quando houver.

Como escrevem Barreyro e Rothen (2014, p. 71) “a criação do Índice Geral de Cursos (IGC), em setembro de 2008, consolidou a influência na educação superior da tendência internacional de uso de indicadores". Tal índice funciona como dado preliminar às visitas in loco e os resultados ficam disponíveis para consulta pública no site do Inep na internet.

\footnotetext{
${ }^{1}$ Média ponderada: média considerando também o número de matrículas em cada um dos cursos avaliados.

${ }^{2}$ Quando a IES não tem programa de pós-graduação stricto senso, este insumo é descartado na elaboração do IGC. 
Um ano depois, em agosto de 2009, o MEC editou a Portaria $\mathrm{n}^{\circ} 821$ anunciando revisões na mecânica pela qual o CPC seria composto. Uma das críticas feitas ao CPC foi atendida: a diminuição do peso do ENADE na composição do referido índice, bem como a opinião dos estudantes em relação aos insumos institucionais. Em contrapartida, aumentou-se o peso pela presença de professores doutores no quadro docente do curso.

Além dessa nova composição do CPC, em 2009, institui-se uma das mudanças mais importantes no sistema de avaliação: o ENADE deixaria de ser amostral e passaria a ser censitário. Barreyro e Rothen (2006, p. 71) apontam que:

\begin{abstract}
Essa mudança foi explicada devido a uma diferença de concepção entre a proposta da CEA e a subjacente aos atuais índices. A utilização de uma amostra, conforme proposto pela CEA em 2004, não é problemática, pois se compreendia que a prova seria apenas um instrumento para diagnóstico do estado da educação superior. Porém, no momento em que o ENADE foi caracterizado como um instrumento para classificação e regulação, as instituições sentiram que a adoção de amostras podia alterar o posicionamento institucional no ranque, ou seja: as amostras permitem certa confiabilidade para conhecer a realidade da educação superior, enquanto o ranque pode gerar desconfianças.
\end{abstract}

Enfim, o ENADE, cuja propósito inicial era o de fornecer dados complementares para a avaliação institucional, passa a ser protagonista do sistema, tal como o Provão. Instituições e estudantes empreendem esforços para "ir bem na prova", e não produzir reflexões sobre os sentidos da formação e aperfeiçoamento institucional.

\title{
Teses e dissertações sobre o SINAES produzidas entre 2004 e 2014
}

Utilizamo-nos de dois indexadores de obras de mestrado e doutorado: Biblioteca Digital de Teses e Dissertações (BDTD) e Banco de Teses e Dissertações da CAPES. No web-site de cada um desses indexadores (http://bdtd.ibct.b e http://bancodeteses.capes.gov.br, respectivamente) utilizamos como descritor a palavra 'sinaes' e procedemos à busca no campo 'resumo' de cada motor de busca.

A Tabela 1 mostra-nos os resultados após a filtragem nossa filtragem considerando: (i) a exclusão das duplicidades 3 ; (ii) somente os trabalhos publicados entre 2004 e 2014; (iii) somente as obras em que o SINAES - ou um de seus componentes - era objeto de pesquisa, de fato, e não um dado tangencial de uma pesquisa em outra área. Ainda em relação a este último

\footnotetext{
3 Tanto na BDTD como no Banco da Capes, há obras indexadas em duplicidade, no interior do próprio indexador. Portanto, após a pesquisa, é necessário verificar os resultados, um a um, para desconsiderar os trabalhos duplicados.
} 
item, muitas vezes tivemos de recorrer à leitura da introdução e considerações finais dos trabalhos para nos certificarmos do que se tratava, realmente, aquela pesquisa.

Tabela 1 - Resultados da busca de teses e dissertações

\begin{tabular}{rccc}
\hline & Mestrado & Doutorado & TOTAL \\
\hline BDTD & 65 & 24 & 89 \\
Banco Capes & 25 & 8 & 33 \\
\hline Total líquido de obras & 13 & 8 & 21 \\
\hline
\end{tabular}

No Quadro 1 apresentamos a lista dessas obras com o devido título, ano da defesa, autores e orientadores e a instituição onde foi defendida. Além disso, criamos um código formado por $\mathrm{M}$ (mestrado) ou $\mathrm{D}$ (doutorado) mais um número, que diz respeito tão somente à ordem de apresentação da lista, que está do mais atual (trabalhos de 2014) para os mais antigos (trabalhos de 2004).

Quadro 1- Obras de mestrado e doutorado produzidas entre 2004 e 2014

\begin{tabular}{|c|c|c|c|c|c|c|c|c|}
\hline Ano & Grau & Título & Autor & Orientador & IES & BDTD & $\begin{array}{l}\text { Banco } \\
\text { Capes }\end{array}$ & Código \\
\hline 2014 & Mestre & $\begin{array}{l}\text { Mapeamento do } \\
\text { conhecimento explícito } \\
\text { na avaliação in loco / } \\
\text { SINAES: o uso da TI na } \\
\text { representação gráfica } \\
\text { das categorias }\end{array}$ & $\begin{array}{l}\text { Marconi } \\
\text { Araujo } \\
\text { Rodrigues }\end{array}$ & $\begin{array}{l}\text { Sandra } \\
\text { Leandro } \\
\text { Pereira }\end{array}$ & UFPB & $X$ & & M1 \\
\hline 2014 & Mestre & $\begin{array}{l}\text { SINAES e os } \\
\text { procedimentos de } \\
\text { avaliação: a construção } \\
\text { de uma nova cultura na } \\
\text { Universidade? }\end{array}$ & $\begin{array}{l}\text { Ana Karolina } \\
\text { Ramalho de } \\
\text { Araujo Rosa }\end{array}$ & $\begin{array}{l}\text { Simone } \\
\text { Magalhães } \\
\text { Brito }\end{array}$ & UFPB & $X$ & & M2 \\
\hline 2014 & Doutor & $\begin{array}{l}\text { Políticas públicas de } \\
\text { avaliação para a } \\
\text { educação superior no } \\
\text { Brasil: autonomia e } \\
\text { produção do } \\
\text { conhecimento }\end{array}$ & $\begin{array}{l}\text { Marijane } \\
\text { Zanotto }\end{array}$ & $\begin{array}{l}\text { Zacarias } \\
\text { Jaegger } \\
\text { Gama }\end{array}$ & UERJ & $X$ & & D1 \\
\hline 2014 & Mestre & $\begin{array}{l}\text { O alcance das } \\
\text { orientações da UNESCO } \\
\text { na elaboração do } \\
\text { Sistema Nacional de } \\
\text { Avaliação da Educação } \\
\text { Superior - SINAES }\end{array}$ & $\begin{array}{l}\text { Armando } \\
\text { Daros Junior }\end{array}$ & $\begin{array}{l}\text { João Jorge } \\
\text { Correa }\end{array}$ & $\begin{array}{l}\text { Univ. } \\
\text { Estadual do } \\
\text { Oeste do } \\
\text { Paraná }\end{array}$ & $X$ & & M3 \\
\hline 2014 & Mestre & $\begin{array}{l}\text { Avaliação institucional: o } \\
\text { caso da UFSCar }\end{array}$ & $\begin{array}{l}\text { Joelma dos } \\
\text { Santos }\end{array}$ & $\begin{array}{l}\text { José Carlos } \\
\text { Rothen }\end{array}$ & UFSCar & $X$ & & M4 \\
\hline 2014 & Mestre & $\begin{array}{l}\text { Autoavaliação } \\
\text { institucional: a realidade } \\
\text { da CPA na prática do } \\
\text { SINAES }\end{array}$ & $\begin{array}{l}\text { Alexandra } \\
\text { Ferreira }\end{array}$ & $\begin{array}{l}\text { Jose Pont } \\
\text { Vidal }\end{array}$ & UFPA & $X$ & & M5 \\
\hline 2014 & Doutor & $\begin{array}{l}\text { Autoavaliação a partir da } \\
\text { ótica dos gestores de } \\
\text { uma instituição de } \\
\text { ensino superior }\end{array}$ & $\begin{array}{l}\text { Nelson } \\
\text { Lambert de } \\
\text { Andrade }\end{array}$ & $\begin{array}{l}\text { Mere } \\
\text { Abramovicz }\end{array}$ & PUC SP & $X$ & & $\mathrm{D} 2$ \\
\hline
\end{tabular}




\begin{tabular}{|c|c|c|c|c|c|c|c|c|}
\hline Ano & Grau & Título & Autor & Orientador & IES & BDTD & $\begin{array}{l}\text { Banco } \\
\text { Capes }\end{array}$ & Código \\
\hline 2014 & Mestre & $\begin{array}{l}\text { A autoavaliação } \\
\text { institucional no ensino } \\
\text { superior: a perspectiva e } \\
\text { estratégia discentes }\end{array}$ & $\begin{array}{l}\text { Marcelo } \\
\text { Leandro } \\
\text { Ferraz Alves }\end{array}$ & $\begin{array}{l}\text { Roger } \\
\text { Marchesini } \\
\text { Quadros } \\
\text { Souza }\end{array}$ & $\begin{array}{l}\text { Univ. } \\
\text { Metodista } \\
\text { de São } \\
\text { Paulo }\end{array}$ & $\mathrm{X}$ & & M6 \\
\hline 2014 & Doutor & $\begin{array}{l}\text { Regular e/ou induzir } \\
\text { qualidade? Os cursos de } \\
\text { pedagogia nos ciclos } \\
\text { avaliativos do SINAES }\end{array}$ & $\begin{array}{l}\text { Claudia } \\
\text { Maffini } \\
\text { Griboski }\end{array}$ & $\begin{array}{l}\text { José Vieira } \\
\text { de Souza }\end{array}$ & UnB & $X$ & & D3 \\
\hline 2014 & Mestre & $\begin{array}{l}\text { O ENADE (Exame } \\
\text { Nacional de } \\
\text { Desempenho de } \\
\text { Estudantes) sob a ótica } \\
\text { de alunos de } \\
\text { administração }\end{array}$ & $\begin{array}{l}\text { Marcel André } \\
\text { Valluis }\end{array}$ & & $\begin{array}{l}\text { Univ. } \\
\text { Católica de } \\
\text { Santos }\end{array}$ & $X$ & & M7 \\
\hline 2014 & Mestre & $\begin{array}{l}\text { Diretrizes curriculares } \\
\text { nacionais do curso de } \\
\text { graduação em farmácia } \\
\text { e o sistema nacional de } \\
\text { avaliação da educação } \\
\text { superior: análise crítico- } \\
\text { reflexiva da prova do } \\
\text { ENADE } 2010\end{array}$ & $\begin{array}{l}\text { Joice Nedel } \\
\text { Ott }\end{array}$ & $\begin{array}{l}\text { Bartira } \\
\text { Ercília } \\
\text { Pinheiro da } \\
\text { Costa }\end{array}$ & UFRGS & $X$ & & M8 \\
\hline 2014 & Doutor & $\begin{array}{l}\text { Implicações do ENADE } \\
\text { para a organização do } \\
\text { trabalho pedagógico e } \\
\text { as práticas avaliativas } \\
\text { em um curso de } \\
\text { pedagogia }\end{array}$ & $\begin{array}{l}\text { Simone Braz } \\
\text { Ferreira } \\
\text { Gontijo }\end{array}$ & $\begin{array}{l}\text { Benigna } \\
\text { Maria de } \\
\text { Freitas Villas } \\
\text { Boas }\end{array}$ & UnB & $X$ & & D4 \\
\hline 2013 & Doutor & $\begin{array}{l}\text { Índice geral de cursos } \\
\text { (IGC) como indicador de } \\
\text { qualidade das } \\
\text { instituições de ensino } \\
\text { superior }\end{array}$ & $\begin{array}{l}\text { Mauro } \\
\text { Afonso Rizzo }\end{array}$ & $\begin{array}{l}\text { Maria } \\
\text { Teresa } \\
\text { Miceli } \\
\text { Kerbauy }\end{array}$ & Unesp & $X$ & & D5 \\
\hline 2013 & Mestre & $\begin{array}{l}\text { A utilização do balanced } \\
\text { scoredard no controle } \\
\text { dos indicadores de } \\
\text { desempenho do sistema } \\
\text { nacional de avaliação da } \\
\text { educação superior }\end{array}$ & $\begin{array}{l}\text { Erik Pereira } \\
\text { Wohnrath }\end{array}$ & $\begin{array}{l}\text { Neusa Maria } \\
\text { Bastos } \\
\text { Fernandes } \\
\text { Santos }\end{array}$ & PUC SP & $X$ & & M9 \\
\hline 2013 & Doutor & $\begin{array}{l}\text { Ensino superior, controle } \\
\text { estatal, avaliação } \\
\text { institucional e o SINAES: } \\
\text { matrizes histórico- } \\
\text { institucionais, } \\
\text { contradições políticas e } \\
\text { perspectivas de } \\
\text { autonomia do ensino } \\
\text { superior brasileiro para } \\
\text { além do SINAES }\end{array}$ & $\begin{array}{l}\text { Reginaldo } \\
\text { Arthus }\end{array}$ & $\begin{array}{l}\text { Cesar } \\
\text { Aparecido } \\
\text { Nunes }\end{array}$ & Unicamp & $X$ & & D6 \\
\hline 2013 & Mestre & $\begin{array}{l}\text { Uma avaliação política } \\
\text { da política de avaliação } \\
\text { da educação superior } \\
\text { brasileira }\end{array}$ & $\begin{array}{l}\text { Pedro Isaac } \\
\text { Ximenes } \\
\text { Lopes }\end{array}$ & $\begin{array}{l}\text { Lincoln } \\
\text { Moraes de } \\
\text { Souza }\end{array}$ & UFRN & $X$ & & M10 \\
\hline 2013 & Mestre & $\begin{array}{l}\text { Gestão de bibliotecas: } \\
\text { avaliação estrutural das } \\
\text { bibliotecas do instituto } \\
\text { federal de educação, } \\
\text { ciência e tecnologia do } \\
\text { Amazonas - IFAM }\end{array}$ & $\begin{array}{l}\text { Odimar José } \\
\text { Ferreira Porto }\end{array}$ & $\begin{array}{l}\text { Celia Regina } \\
\text { Simonetti }\end{array}$ & UFAM & $X$ & & M11 \\
\hline 2013 & Mestre & $\begin{array}{l}\text { Uma análise da } \\
\text { sustentabilidade } \\
\text { financeira da faculdade } \\
\text { independente do } \\
\text { nordeste FAINOR - } \\
\text { através dos indicadores } \\
\text { do sistema nacional - } \\
\text { SINAES/MEC }\end{array}$ & $\begin{array}{l}\text { Edvaldo } \\
\text { Pedreira } \\
\text { Gama Filho }\end{array}$ & $\begin{array}{l}\text { Eladio Jose } \\
\text { de Goes } \\
\text { Brennand }\end{array}$ & UFPB & $X$ & & M12 \\
\hline
\end{tabular}




\begin{tabular}{|c|c|c|c|c|c|c|c|c|}
\hline Ano & Grau & Título & Autor & Orientador & IES & BDTD & $\begin{array}{l}\text { Banco } \\
\text { Capes }\end{array}$ & Código \\
\hline 2013 & Mestre & $\begin{array}{l}\text { O significado da } \\
\text { autoavaliação } \\
\text { institucional na } \\
\text { perspectiva de técnicos- } \\
\text { administrativos da } \\
\text { universidade federal de } \\
\text { Uberlândia }\end{array}$ & $\begin{array}{l}\text { Ana Elisa de } \\
\text { Souza } \\
\text { Falleiros }\end{array}$ & $\begin{array}{l}\text { Marcio } \\
\text { Lopes } \\
\text { Pimenta }\end{array}$ & UFU & $\mathrm{X}$ & & M13 \\
\hline 2013 & Mestre & $\begin{array}{l}\text { Cobertura do acervo do } \\
\text { sistema de bibliotecas } \\
\text { da UFC: importância } \\
\text { para a avaliação do } \\
\text { MEC }\end{array}$ & $\begin{array}{l}\text { Leila Denise } \\
\text { Cabral Pinto }\end{array}$ & & UFC & $X$ & & M14 \\
\hline 2013 & Mestre & $\begin{array}{l}\text { Estudo do processo de } \\
\text { avaliação interna - } \\
\text { ferramenta de tomada } \\
\text { de decisão, de } \\
\text { autocontrole, de } \\
\text { autoconhecimento e de } \\
\text { melhoria na gestão de } \\
\text { universidades e } \\
\text { institutos federais }\end{array}$ & $\begin{array}{l}\text { Lucilene } \\
\text { Rebouças de } \\
\text { Oliveira }\end{array}$ & $\begin{array}{l}\text { Daniel } \\
\text { Nascimento } \\
\text { e Silva }\end{array}$ & UFAM & $\mathrm{X}$ & & M15 \\
\hline 2013 & Mestre & $\begin{array}{l}\text { Autoavaliação } \\
\text { institucional na } \\
\text { dimensão do SINAES } \\
\text { comunicação com a } \\
\text { sociedade: estudo de } \\
\text { múltiplos casos em } \\
\text { instituições de ensino } \\
\text { superior do Rio Grande } \\
\text { do Norte }\end{array}$ & $\begin{array}{l}\text { Rosana } \\
\text { Curvelo de } \\
\text { Souza }\end{array}$ & $\begin{array}{l}\text { Miguel } \\
\text { Eduardo } \\
\text { Moreno } \\
\text { Añez }\end{array}$ & UFRN & $X$ & & M16 \\
\hline 2013 & Mestre & $\begin{array}{l}\text { Avaliação institucional } \\
\text { de IES: reflexões sobre } \\
\text { compatibilidade de três } \\
\text { modelos de } \\
\text { autoavaliação SINAES, } \\
\text { FNQ e CAF }\end{array}$ & $\begin{array}{l}\text { Fabio Redin } \\
\text { do } \\
\text { Nascimento }\end{array}$ & $\begin{array}{l}\text { Alberto } \\
\text { Souza } \\
\text { Schmidt }\end{array}$ & UFSM & $X$ & & M17 \\
\hline 2013 & Mestre & $\begin{array}{l}\text { Sentidos e significados } \\
\text { do índice geral de cursos } \\
\text { na regulação da } \\
\text { qualidade da educação } \\
\text { superior }\end{array}$ & $\begin{array}{l}\text { Paola Matos } \\
\text { da Hora }\end{array}$ & $\begin{array}{l}\text { José Vieira } \\
\text { de Sousa }\end{array}$ & UnB & $X$ & & M18 \\
\hline 2013 & Doutor & $\begin{array}{l}\text { Exame Nacional de } \\
\text { Desempenho dos } \\
\text { estudantes: uma análise } \\
\text { do uso dos resultados no } \\
\text { curso de pedagogia da } \\
\text { UEMA }\end{array}$ & $\begin{array}{l}\text { Ana Lúcia } \\
\text { Cunha } \\
\text { Duarte }\end{array}$ & $\begin{array}{l}\text { José Vieira } \\
\text { de Sousa }\end{array}$ & UnB & $X$ & & D7 \\
\hline 2013 & Mestre & $\begin{array}{l}\text { Exame Nacional de } \\
\text { Desempenho de } \\
\text { Estudantes: impactos na } \\
\text { IES e estratégias de } \\
\text { aprimoramento } \\
\text { institucional. Um estudo } \\
\text { a partir da produção } \\
\text { científica brasileira } \\
\text { (2004-2010) }\end{array}$ & $\begin{array}{l}\text { Adauto Marin } \\
\text { Molck }\end{array}$ & $\begin{array}{l}\text { Adolfo } \\
\text { Ignacio } \\
\text { Calderón }\end{array}$ & $\begin{array}{c}\text { PUC } \\
\text { Campinas }\end{array}$ & $X$ & & M19 \\
\hline 2012 & Mestre & $\begin{array}{l}\text { Avaliação da educação } \\
\text { superior a distância e } \\
\text { seu papel no Estado } \\
\text { atual: uma análise do } \\
\text { SINAES }\end{array}$ & $\begin{array}{l}\text { Adna Reale } \\
\text { dos Reis } \\
\text { Guimarães }\end{array}$ & $\begin{array}{l}\text { Rosilda } \\
\text { Arruda } \\
\text { Ferreira }\end{array}$ & UFBA & $X$ & $X$ & M20 \\
\hline 2012 & Mestre & $\begin{array}{l}\text { Avaliação e qualidade } \\
\text { para educação superior } \\
\text { a distância de Santa } \\
\text { Caterina: desafios para o } \\
\text { SINAES }\end{array}$ & $\begin{array}{l}\text { Rafael } \\
\text { Pereira } \\
\text { Ocampo } \\
\text { More }\end{array}$ & $\begin{array}{l}\text { Alexandre } \\
\text { Marino } \\
\text { Costa }\end{array}$ & UFSC & $X$ & $X$ & M21 \\
\hline 2012 & Mestre & $\begin{array}{l}\text { Sistema Nacional de } \\
\text { avaliação da educação } \\
\text { superior - SINAES: } \\
\text { desafios e } \\
\text { compromissos na FIAR } \\
\text { - Faculdades Integradas } \\
\text { de Ariquemes }\end{array}$ & Gilmar Utzig & $\begin{array}{l}\text { Andreia da } \\
\text { Silva } \\
\text { Quintanilha } \\
\text { Sousa }\end{array}$ & UFRO & & $X$ & M22 \\
\hline
\end{tabular}




\begin{tabular}{|c|c|c|c|c|c|c|c|c|}
\hline Ano & Grau & Título & Autor & Orientador & IES & BDTD & $\begin{array}{l}\text { Banco } \\
\text { Capes }\end{array}$ & Código \\
\hline 2012 & Mestre & $\begin{array}{l}\text { A acreditação no } \\
\text { sistema federal de } \\
\text { ensino superior e seus } \\
\text { reflexos na rotina } \\
\text { institucional da UFJF }\end{array}$ & $\begin{array}{l}\text { Rosa Maria } \\
\text { dos Santos } \\
\text { Manso } \\
\text { Sakamoto }\end{array}$ & $\begin{array}{l}\text { Fernando } \\
\text { Tavares } \\
\text { Junior }\end{array}$ & UFJF & & $X$ & M23 \\
\hline 2012 & Mestre & $\begin{array}{l}\text { Avaliação da educação } \\
\text { superior na intersecção } \\
\text { de políticas sistêmicas e } \\
\text { institucional }\end{array}$ & $\begin{array}{l}\text { Marianne } \\
\text { Pereira de } \\
\text { Souza }\end{array}$ & $\begin{array}{l}\text { Giselle } \\
\text { Cristina } \\
\text { Martins Real }\end{array}$ & $\begin{array}{l}\text { Univ. } \\
\text { Federal } \\
\text { Grande } \\
\text { Dourados }\end{array}$ & & $X$ & M24 \\
\hline 2012 & Doutor & $\begin{array}{l}\text { Contribuições de uma } \\
\text { política pública de } \\
\text { avaliação institucional } \\
\text { para a Universidade } \\
\text { Federal do Amapá }\end{array}$ & $\begin{array}{l}\text { Maria Nazaré } \\
\text { do } \\
\text { Nascimento } \\
\text { Guimarães }\end{array}$ & $\begin{array}{l}\text { Regina } \\
\text { Maria } \\
\text { Simões } \\
\text { Puccinelli } \\
\text { Tancredi }\end{array}$ & UFSCar & $X$ & $X$ & D8 \\
\hline 2012 & Mestre & $\begin{array}{l}\text { SINAES - sistema } \\
\text { nacional da avaliação da } \\
\text { educação superior: da } \\
\text { concepção às } \\
\text { contradições }\end{array}$ & $\begin{array}{l}\text { Rejane } \\
\text { Tavares } \\
\text { Lessa }\end{array}$ & $\begin{array}{l}\text { Paulo Sérgio } \\
\text { Braga } \\
\text { Tafner }\end{array}$ & $\begin{array}{l}\text { Univ. } \\
\text { Candido } \\
\text { Mendes }\end{array}$ & & $X$ & M25 \\
\hline 2012 & Doutor & $\begin{array}{l}\text { Avaliação da } \\
\text { comunicação } \\
\text { universidade-sociedade: } \\
\text { gestão de } \\
\text { relacionamentos face } \\
\text { aos agentes com } \\
\text { influência }\end{array}$ & $\begin{array}{l}\text { Ana Karin } \\
\text { Nunes }\end{array}$ & $\begin{array}{l}\text { Denise } \\
\text { Balarine } \\
\text { Cavalheiro } \\
\text { Leite }\end{array}$ & UFRGS & $X$ & $X$ & D9 \\
\hline 2012 & Mestre & $\begin{array}{l}\text { Autoavaliação como } \\
\text { instrumento de gestão } \\
\text { na educação superior: o } \\
\text { caso do instituto federal } \\
\text { de educação, ciência e } \\
\text { tecnologia de Goiás IFG }\end{array}$ & $\begin{array}{l}\text { Angela Maria } \\
\text { de Menezes }\end{array}$ & $\begin{array}{l}\text { José Vieira } \\
\text { de Sousa }\end{array}$ & UnB & $X$ & $X$ & M26 \\
\hline 2012 & Mestre & $\begin{array}{l}\text { A mediação do SINAES } \\
\text { no processo de } \\
\text { avaliação das bibliotecas } \\
\text { universitárias em } \\
\text { fortaleza }\end{array}$ & $\begin{array}{l}\text { Maria Aurea } \\
\text { Montenegro } \\
\text { Albuquerque } \\
\text { Guerra }\end{array}$ & $\begin{array}{l}\text { Francisco } \\
\text { Ari de } \\
\text { Andrade }\end{array}$ & UFC & $X$ & $X$ & M27 \\
\hline 2012 & Mestre & $\begin{array}{l}\text { Meta-avaliando uma } \\
\text { autoavaliação no âmbito } \\
\text { do SINAES }\end{array}$ & $\begin{array}{l}\text { Marcia da } \\
\text { Silveira } \\
\text { Ferreira }\end{array}$ & $\begin{array}{l}\text { Ligia Silva } \\
\text { Leite }\end{array}$ & $\begin{array}{c}\text { Fund. } \\
\text { Cesgranrio }\end{array}$ & & $X$ & M28 \\
\hline 2012 & Mestre & $\begin{array}{l}\text { Avaliação institucional } \\
\text { de organizações de } \\
\text { ensino superior: um } \\
\text { estudo da abrangência } \\
\text { semântica e formal da } \\
\text { avaliação de } \\
\text { desempenho em um } \\
\text { modelo de autoavaliação } \\
\text { de uma IFE paranaense }\end{array}$ & $\begin{array}{l}\text { Elsi do Rocio } \\
\text { Cardoso } \\
\text { Alano }\end{array}$ & $\begin{array}{l}\text { Queila } \\
\text { Regina } \\
\text { Souza }\end{array}$ & $\begin{array}{l}\text { Univ. } \\
\text { Positivo }\end{array}$ & & $X$ & M29 \\
\hline 2012 & Mestre & $\begin{array}{l}\text { Autoavaliação } \\
\text { institucional: da } \\
\text { participação à percepção } \\
\text { dos resultados na ótica } \\
\text { do corpo discente }\end{array}$ & $\begin{array}{l}\text { Rodrigo Julio } \\
\text { Alves de } \\
\text { Almeida }\end{array}$ & $\begin{array}{l}\text { Celia Maria } \\
\text { Haas }\end{array}$ & $\begin{array}{l}\text { Univ. } \\
\text { Cidade de } \\
\text { São Paulo }\end{array}$ & & $X$ & M30 \\
\hline 2012 & Mestre & $\begin{array}{l}\text { Um modelo para apoiar } \\
\text { a gestão educacional } \\
\text { das IES com descoberta } \\
\text { de conhecimento } \\
\text { baseado no processo de } \\
\text { autoavaliação } \\
\text { institucional (SINAES) }\end{array}$ & $\begin{array}{l}\text { Leopoldo } \\
\text { Ramos de } \\
\text { Oliveira }\end{array}$ & $\begin{array}{l}\text { Patrick } \\
\text { Henrique da } \\
\text { Silva Brito }\end{array}$ & UFAL & & $X$ & M31 \\
\hline 2012 & Mestre & $\begin{array}{l}\text { Avaliação do } \\
\text { instrumento utilizado } \\
\text { pela UNIRIO em sua } \\
\text { autoavaliação } \\
\text { institucional }\end{array}$ & $\begin{array}{l}\text { Maria do } \\
\text { Rosário } \\
\text { Villarino } \\
\text { Soares Leão }\end{array}$ & $\begin{array}{l}\text { Angela } \\
\text { Carrancho } \\
\text { da Silva }\end{array}$ & $\begin{array}{c}\text { Fund. } \\
\text { Cesgranrio }\end{array}$ & & $X$ & M32 \\
\hline 2012 & Mestre & $\begin{array}{l}\text { SINAES: indicadores de } \\
\text { qualidade de cursos no } \\
\text { ensino superior e } \\
\text { reprodução social }\end{array}$ & $\begin{array}{l}\text { Leandro } \\
\text { Berchielli }\end{array}$ & $\begin{array}{l}\text { Leda maria } \\
\text { de Oliveira } \\
\text { Rodrigues }\end{array}$ & PUC SP & $X$ & $X$ & M33 \\
\hline
\end{tabular}




\begin{tabular}{|c|c|c|c|c|c|c|c|c|}
\hline Ano & Grau & Título & Autor & Orientador & IES & BDTD & $\begin{array}{l}\text { Banco } \\
\text { Capes }\end{array}$ & Código \\
\hline 2012 & Doutor & $\begin{array}{l}\text { Determinantes do } \\
\text { desempenho acadêmico } \\
\text { dos alunos dos cursos } \\
\text { de ciências contábeis }\end{array}$ & $\begin{array}{l}\text { Nalbia de } \\
\text { Araujo } \\
\text { Santos }\end{array}$ & $\begin{array}{l}\text { Luis } \\
\text { Eduardo } \\
\text { Afonso }\end{array}$ & USP & $\mathrm{X}$ & $x$ & D10 \\
\hline 2012 & Mestre & $\begin{array}{l}\text { Conceito cinco no } \\
\text { ENADE em cursos de } \\
\text { pedagogia: que } \\
\text { referências estão em } \\
\text { jogo? }\end{array}$ & $\begin{array}{l}\text { Eleni } \\
\text { Hosokawa } \\
\text { Wordell }\end{array}$ & $\begin{array}{l}\text { José Vieira } \\
\text { de Sousa }\end{array}$ & UnB & $x$ & $X$ & M34 \\
\hline 2012 & Mestre & $\begin{array}{l}\text { O ENADE e a gestão de } \\
\text { cursos superiores de } \\
\text { tecnologia em } \\
\text { instituições de educação } \\
\text { superior no setor privado }\end{array}$ & $\begin{array}{l}\text { Denise de } \\
\text { Fatima } \\
\text { Alonso }\end{array}$ & $\begin{array}{l}\text { Maria } \\
\text { Angélica } \\
\text { Rodrigues } \\
\text { Martins }\end{array}$ & $\begin{array}{l}\text { Univ. } \\
\text { Católica de } \\
\text { Santos }\end{array}$ & $\mathrm{X}$ & $X$ & M35 \\
\hline 2011 & Mestre & $\begin{array}{l}\text { Avaliação institucional: } \\
\text { entre políticas e práticas }\end{array}$ & $\begin{array}{l}\text { Vera Maria } \\
\text { Barbosa }\end{array}$ & $\begin{array}{l}\text { Fausto dos } \\
\text { Santos } \\
\text { Amaral Filho }\end{array}$ & $\begin{array}{l}\text { Univ. Tuiuti } \\
\text { do Paraná }\end{array}$ & $X$ & $X$ & M36 \\
\hline 2011 & Mestre & $\begin{array}{l}\text { Contribuições dos } \\
\text { resultados da avaliação } \\
\text { institucional para a } \\
\text { gestão universitária: um } \\
\text { estudo de caso em uma } \\
\text { IES privada de Salvador }\end{array}$ & $\begin{array}{l}\text { Iracema dos } \\
\text { Santos } \\
\text { Lemos }\end{array}$ & $\begin{array}{l}\text { Robinson } \\
\text { Moreira } \\
\text { Tenorio }\end{array}$ & UFBA & & $\mathrm{X}$ & M37 \\
\hline 2011 & Doutor & $\begin{array}{l}\text { O discurso da avaliação } \\
\text { institucional trajetória } \\
\text { articulada no campo das } \\
\text { políticas educacionais: } \\
\text { um estudo de caso }\end{array}$ & $\begin{array}{l}\text { Katia Silva } \\
\text { Cunha }\end{array}$ & $\begin{array}{l}\text { Alfredo } \\
\text { Macedo } \\
\text { Gomes }\end{array}$ & UFPE & $X$ & $X$ & D11 \\
\hline 2011 & Mestre & $\begin{array}{l}\text { Políticas de avaliação da } \\
\text { educação superior da } \\
\text { Universidade Federal do } \\
\text { Tocantins UFT no } \\
\text { Contexto do SINAES: } \\
\text { entre avaliadores e } \\
\text { avaliados }\end{array}$ & $\begin{array}{l}\text { Maria de } \\
\text { Fátima } \\
\text { Conceição }\end{array}$ & $\begin{array}{l}\text { Alcides } \\
\text { Fernando } \\
\text { Gussi }\end{array}$ & UFC & $X$ & $X$ & M38 \\
\hline 2011 & Mestre & $\begin{array}{l}\text { Análise da Lei do } \\
\text { SINAES e seus } \\
\text { resultados como } \\
\text { instrumento de controle } \\
\text { do estado }\end{array}$ & $\begin{array}{l}\text { Natalia de } \\
\text { Oliveira } \\
\text { Albuquerque }\end{array}$ & $\begin{array}{l}\text { Maxweel } \\
\text { Veras } \\
\text { Rodrigues }\end{array}$ & UFC & $X$ & $X$ & M39 \\
\hline 2011 & Mestre & $\begin{array}{l}\text { Avaliação do processo } \\
\text { de modernização da } \\
\text { biblioteca da } \\
\text { universidade federal de } \\
\text { Tocantins, campus } \\
\text { universitário de Palmas }\end{array}$ & $\begin{array}{l}\text { Heloisa dos } \\
\text { Santos Brasil }\end{array}$ & $\begin{array}{l}\text { Lea } \\
\text { Carvalho } \\
\text { Rodrigues }\end{array}$ & UFC & $X$ & $X$ & M40 \\
\hline 2011 & Mestre & $\begin{array}{l}\text { O novo modelo para a } \\
\text { educação profissional e } \\
\text { tecnológica e a } \\
\text { avaliação institucional: } \\
\text { efeitos das políticas } \\
\text { públicas sobre a } \\
\text { configuração do Instituto } \\
\text { Federal de Santa } \\
\text { Catarina }\end{array}$ & $\begin{array}{l}\text { Maria Alice } \\
\text { Sens } \\
\text { Brezinski }\end{array}$ & $\begin{array}{l}\text { Luis Enrique } \\
\text { Aguilar }\end{array}$ & Unicamp & $X$ & $X$ & M41 \\
\hline 2011 & Doutor & $\begin{array}{l}\text { Instituições de ensino } \\
\text { superior e } \\
\text { responsabilidade social: } \\
\text { um estudo sobre as } \\
\text { representações de } \\
\text { liderança da educação } \\
\text { superior brasileira }\end{array}$ & $\begin{array}{l}\text { Marcia } \\
\text { Regina } \\
\text { Chrispim } \\
\text { Alvares } \\
\text { Rosetto }\end{array}$ & $\begin{array}{l}\text { Regina } \\
\text { Lucia Giffoni } \\
\text { Luz de Brito }\end{array}$ & PUC SP & $X$ & $X$ & D12 \\
\hline 2011 & Mestre & $\begin{array}{l}\text { A autoavaliação } \\
\text { proposta pelo SINAES o } \\
\text { contexto de mudanças } \\
\text { da educação profissional } \\
\text { e tecnológica: um estudo } \\
\text { de caso no instituto } \\
\text { federal do norte de } \\
\text { Minas Gerais }\end{array}$ & $\begin{array}{l}\text { Valesca } \\
\text { Rodrigues de } \\
\text { Souza }\end{array}$ & $\begin{array}{l}\text { Bernardo } \\
\text { Kipnis }\end{array}$ & UnB & $X$ & & M42 \\
\hline
\end{tabular}




\begin{tabular}{|c|c|c|c|c|c|c|c|c|}
\hline Ano & Grau & Título & Autor & Orientador & IES & BDTD & $\begin{array}{l}\text { Banco } \\
\text { Capes }\end{array}$ & Código \\
\hline 2011 & Doutor & $\begin{array}{l}\text { O processo de } \\
\text { autoavaliação da UFMA } \\
\text { (2004-2006) no contexto } \\
\text { regulatório da educação } \\
\text { superior }\end{array}$ & $\begin{array}{l}\text { Lucinete } \\
\text { Marques } \\
\text { Lima }\end{array}$ & $\begin{array}{l}\text { Cândido } \\
\text { Giraldez } \\
\text { Vieitez }\end{array}$ & Unesp & $\mathrm{X}$ & $X$ & D13 \\
\hline 2011 & Mestre & $\begin{array}{l}\text { Diagnóstico de } \\
\text { implantação da } \\
\text { autoavaliação nas } \\
\text { faculdades privadas de } \\
\text { Salvador na visão dos } \\
\text { coordenadores da } \\
\text { comissão própria de } \\
\text { avaliação }\end{array}$ & $\begin{array}{l}\text { Sabrina } \\
\text { Oliveira } \\
\text { Caribe }\end{array}$ & $\begin{array}{l}\text { Xisto Lucas } \\
\text { Travassos } \\
\text { Junior }\end{array}$ & $\begin{array}{l}\text { Fac. } \\
\text { Tecnologia } \\
\text { SENAI } \\
\text { Cimatec }\end{array}$ & & $X$ & M43 \\
\hline 2011 & Mestre & $\begin{array}{l}\text { Avaliação do perfil de } \\
\text { egressos do curso de } \\
\text { graduação em } \\
\text { administração: a } \\
\text { inserção no mercado de } \\
\text { trabalho }\end{array}$ & $\begin{array}{l}\text { Selma } \\
\text { Barbato }\end{array}$ & $\begin{array}{l}\text { Angela } \\
\text { Carrancho } \\
\text { da Silva }\end{array}$ & $\begin{array}{c}\text { Fund. } \\
\text { Cesgranrio }\end{array}$ & & $X$ & M44 \\
\hline 2011 & Doutor & $\begin{array}{l}\text { Avaliação da educação } \\
\text { superior: condições, } \\
\text { processos e efeitos da } \\
\text { autoavaliação nos } \\
\text { cursos de graduação da } \\
\text { UFBA }\end{array}$ & $\begin{array}{l}\text { Débora Alfaia } \\
\text { da Cunha }\end{array}$ & $\begin{array}{l}\text { Marilia } \\
\text { Fonseca }\end{array}$ & UnB & $X$ & & D14 \\
\hline 2011 & Mestre & $\begin{array}{l}\text { Avaliação institucional: } \\
\text { interlocução entre } \\
\text { autoavaliações na } \\
\text { perspectiva do SINAES } \\
\text { e do Gespública }\end{array}$ & $\begin{array}{l}\text { Alberto } \\
\text { Farias Filho }\end{array}$ & $\begin{array}{l}\text { Wagner } \\
\text { Bandeira } \\
\text { Andriola }\end{array}$ & UFC & $X$ & $X$ & M45 \\
\hline 2011 & Doutor & $\begin{array}{l}\text { As contribuições da } \\
\text { avaliação da graduação } \\
\text { para a melhoria da } \\
\text { qualidade da educação } \\
\text { superior }\end{array}$ & $\begin{array}{l}\text { Maria Antonia } \\
\text { Brandão de } \\
\text { Andrade }\end{array}$ & & UFBA & $X$ & $X$ & D15 \\
\hline 2011 & Doutor & $\begin{array}{l}\text { Abordagem dos } \\
\text { conteúdos de biologia } \\
\text { celular em cursos de } \\
\text { ciências biológicas e sua } \\
\text { relação com as } \\
\text { avaliações nacionais }\end{array}$ & $\begin{array}{l}\text { Viktoria } \\
\text { Kovesky } \\
\text { Ribeiro }\end{array}$ & $\begin{array}{l}\text { Angelo Luiz } \\
\text { Cortelazzo }\end{array}$ & Unicamp & $x$ & $X$ & D16 \\
\hline 2011 & Mestre & $\begin{array}{l}\text { As repercussões do } \\
\text { ENADE na gestão da } \\
\text { universidade pública } \\
\text { brasileira: o caso da UnB }\end{array}$ & $\begin{array}{l}\text { Rodrigo da } \\
\text { Silva Pereira }\end{array}$ & $\begin{array}{l}\text { Marilia } \\
\text { Fonseca }\end{array}$ & UnB & $X$ & & M46 \\
\hline 2010 & Mestre & $\begin{array}{l}\text { SINAES: as diferentes } \\
\text { faces da avaliação na } \\
\text { UFRN }\end{array}$ & $\begin{array}{l}\text { Shirmenia } \\
\text { Kaline da } \\
\text { Silva Nunes } \\
\text { Eussen }\end{array}$ & $\begin{array}{l}\text { Alda Maria } \\
\text { Duarte } \\
\text { Araujo } \\
\text { Castro }\end{array}$ & UFRN & $X$ & & M47 \\
\hline 2010 & Mestre & $\begin{array}{l}\text { O exame nacional de } \\
\text { desempenho de } \\
\text { estudantes no curso de } \\
\text { pedagogia da UnB: } \\
\text { avanços, limites e } \\
\text { desafios }\end{array}$ & $\begin{array}{l}\text { Maria Luiza } \\
\text { Nogueira } \\
\text { Rangel }\end{array}$ & $\begin{array}{l}\text { José Vieira } \\
\text { de Sousa }\end{array}$ & UnB & $X$ & & M48 \\
\hline 2010 & Mestre & $\begin{array}{l}\text { Avaliação da qualidade } \\
\text { dos serviços das } \\
\text { bibliotecas universitárias } \\
\text { pelos usuários discentes }\end{array}$ & $\begin{array}{l}\text { Neiliane } \\
\text { Alves } \\
\text { Bezerra }\end{array}$ & $\begin{array}{l}\text { Wagner } \\
\text { Bandeira } \\
\text { Andriola }\end{array}$ & UFC & $X$ & & M49 \\
\hline 2010 & Mestre & $\begin{array}{l}\text { Autoavaliação nas } \\
\text { instituições de ensino } \\
\text { superior do Ceará sob a } \\
\text { égide do sistema } \\
\text { nacional da educação } \\
\text { superior - SINAES }\end{array}$ & $\begin{array}{l}\text { Claudia } \\
\text { Ibiapina Lima }\end{array}$ & $\begin{array}{l}\text { Wagner } \\
\text { Bandeira } \\
\text { Andriola }\end{array}$ & UFC & $X$ & & M50 \\
\hline 2010 & Doutor & $\begin{array}{l}\text { O processo de } \\
\text { autoavaliação } \\
\text { institucional proposto no } \\
\text { sistema nacional de } \\
\text { avaliação da educação } \\
\text { superior (SINAES) para } \\
\text { as instituições públicas e } \\
\text { privadas }\end{array}$ & $\begin{array}{l}\text { Elisa Antonia } \\
\text { Ribeiro }\end{array}$ & $\begin{array}{l}\text { Mara Rubia } \\
\text { Alves } \\
\text { Marques }\end{array}$ & UFU & $X$ & & D17 \\
\hline
\end{tabular}




\begin{tabular}{|c|c|c|c|c|c|c|c|c|}
\hline Ano & Grau & Título & Autor & Orientador & IES & BDTD & $\begin{array}{l}\text { Banco } \\
\text { Capes }\end{array}$ & Código \\
\hline 2010 & Doutor & $\begin{array}{l}\text { Autoavaliação } \\
\text { institucional da } \\
\text { educação superior: uma } \\
\text { experiência brasileira e } \\
\text { suas implicações para a } \\
\text { educação superior de } \\
\text { Timor Leste }\end{array}$ & $\begin{array}{l}\text { Francisco } \\
\text { Miguel } \\
\text { Martins }\end{array}$ & $\begin{array}{l}\text { Robert Evan } \\
\text { Verhine }\end{array}$ & UFBA & $\bar{X}$ & & D18 \\
\hline 2010 & Mestre & $\begin{array}{l}\text { Autoavaliação } \\
\text { institucional na Rede } \\
\text { Federal de Educação } \\
\text { Tecnológica: análise da } \\
\text { implementação do } \\
\text { SINAES }\end{array}$ & $\begin{array}{l}\text { Rivailda } \\
\text { Silveira } \\
\text { Nunes de } \\
\text { Argollo }\end{array}$ & $\begin{array}{l}\text { Robinson } \\
\text { Moreira } \\
\text { Tenório }\end{array}$ & UFBA & $X$ & & M51 \\
\hline 2009 & Mestre & $\begin{array}{l}\text { Proposta de metodologia } \\
\text { de implantação de um } \\
\text { planejamento estratégico } \\
\text { com o uso das } \\
\text { dimensões de um } \\
\text { sistema de avaliação } \\
\text { SINAES: um estudo de } \\
\text { caso }\end{array}$ & $\begin{array}{l}\text { Ney Izaguirry } \\
\text { de Freitas Jr }\end{array}$ & $\begin{array}{l}\text { Alberto } \\
\text { Souza } \\
\text { Schmidt }\end{array}$ & UFSM & $X$ & & M52 \\
\hline 2009 & Mestre & $\begin{array}{l}\text { Avaliação institucional } \\
\text { de IES: reflexões sobre } \\
\text { a compatibilidade dos } \\
\text { indicadores de avaliação } \\
\text { externa do SINAES com } \\
\text { os critérios de } \\
\text { excelência da FNQ }\end{array}$ & $\begin{array}{l}\text { Regis } \\
\text { Simeão } \\
\text { Saldanha } \\
\text { Fagundes }\end{array}$ & $\begin{array}{l}\text { Alberto } \\
\text { Souza } \\
\text { Schmidt }\end{array}$ & UFSM & $X$ & & M53 \\
\hline 2009 & Doutor & $\begin{array}{l}\text { Características da } \\
\text { implementação do } \\
\text { sistema de avaliação da } \\
\text { educação superior } \\
\text { (SINAES) em } \\
\text { instituições de ensino } \\
\text { superior }\end{array}$ & $\begin{array}{l}\text { Jorge Luiz } \\
\text { Lordêlo de } \\
\text { Sales Ribeiro }\end{array}$ & $\begin{array}{l}\text { Robert Evan } \\
\text { Verhine }\end{array}$ & UFBA & $X$ & & D20 \\
\hline 2009 & Doutor & $\begin{array}{l}\text { O caráter público do } \\
\text { SINAES e seu potencial } \\
\text { de transformar o } \\
\text { currículo das } \\
\text { universidades }\end{array}$ & $\begin{array}{l}\text { Klinger Luiz } \\
\text { de Oliveira } \\
\text { Sousa }\end{array}$ & $\begin{array}{l}\text { Isabel } \\
\text { Franchi } \\
\text { Cappelletti }\end{array}$ & PUC SP & $X$ & & D19 \\
\hline 2009 & Mestre & $\begin{array}{l}\text { O uso dos resultados do } \\
\text { Exame Nacional de } \\
\text { Desempenho dos } \\
\text { Estudantes nos cursos } \\
\text { de física da } \\
\text { Universidade de Brasília } \\
\text { e da Universidade } \\
\text { Católica de Brasília } \\
\text { (2005) }\end{array}$ & $\begin{array}{l}\text { Carla de } \\
\text { Borja Reis }\end{array}$ & $\begin{array}{l}\text { José Vieira } \\
\text { de Sousa }\end{array}$ & UnB & $X$ & & M55 \\
\hline 2009 & Mestre & $\begin{array}{l}\text { Análise das } \\
\text { representações sociais } \\
\text { da comunidade interna } \\
\text { da Universidade Federal } \\
\text { do Ceará acerca da } \\
\text { autoavaliação } \\
\text { institucional }\end{array}$ & $\begin{array}{l}\text { Laura Alves } \\
\text { de Souza }\end{array}$ & $\begin{array}{l}\text { Wagner } \\
\text { Bandeira } \\
\text { Andriola }\end{array}$ & UFC & $X$ & & M55 \\
\hline 2009 & Mestre & $\begin{array}{l}\text { Avaliação do ensino } \\
\text { superior: a dinâmica de } \\
\text { implementação do } \\
\text { SINAES nas } \\
\text { universidades federais } \\
\text { no tocante ao } \\
\text { instrumento de avaliação } \\
\text { interna - CPA }\end{array}$ & $\begin{array}{l}\text { Assis Leão } \\
\text { da Silva }\end{array}$ & $\begin{array}{l}\text { Alfredo } \\
\text { Macedo } \\
\text { Gomes }\end{array}$ & UFPE & $X$ & & M56 \\
\hline 2009 & Mestre & $\begin{array}{l}\text { A vivência dos } \\
\text { coordenadores de curso } \\
\text { de enfermagem em } \\
\text { relação ao Sistema } \\
\text { Nacional de Avaliação } \\
\text { do Ensino Superior } \\
\text { (SINAES) }\end{array}$ & $\begin{array}{l}\text { Alessandra } \\
\text { Santos de } \\
\text { Paula }\end{array}$ & $\begin{array}{l}\text { Maria } \\
\text { Madalena } \\
\text { Januário } \\
\text { Leite }\end{array}$ & USP & $X$ & & M57 \\
\hline
\end{tabular}




\begin{tabular}{|c|c|c|c|c|c|c|c|c|}
\hline Ano & Grau & Título & Autor & Orientador & IES & BDTD & $\begin{array}{l}\text { Banco } \\
\text { Capes }\end{array}$ & Código \\
\hline 2009 & Mestre & $\begin{array}{l}\text { Fatores institucionais } \\
\text { associados à eficácia } \\
\text { educacional dos cursos } \\
\text { de graduação da } \\
\text { Universidade Federal do } \\
\text { Ceará (UFC): a opinião } \\
\text { dos coordenadores }\end{array}$ & $\begin{array}{l}\text { Aline Soares } \\
\text { Campos }\end{array}$ & $\begin{array}{l}\text { Wagner } \\
\text { Bandeira } \\
\text { Andriola }\end{array}$ & UFC & $\mathrm{X}$ & & M58 \\
\hline 2008 & Mestre & $\begin{array}{l}\text { O balanced scorecard } \\
\text { como instrumento de } \\
\text { gestão à luz dos } \\
\text { indicadores do sistema } \\
\text { nacional de avaliação da } \\
\text { educação superior }\end{array}$ & $\begin{array}{l}\text { Sérgio } \\
\text { Ricardo } \\
\text { Bezerra dos } \\
\text { Santos }\end{array}$ & $\begin{array}{l}\text { Aneide } \\
\text { Oliveira } \\
\text { Araujo }\end{array}$ & UnB & $X$ & & M59 \\
\hline 2008 & Mestre & $\begin{array}{l}\text { Uma modelagem de } \\
\text { indicadores de } \\
\text { desempenho para } \\
\text { instituições de ensino } \\
\text { superior no Brasil na } \\
\text { abordagem do balanced } \\
\text { scorecard: um estudo } \\
\text { com instituições privadas }\end{array}$ & $\begin{array}{l}\text { Ronald Fabio } \\
\text { de Paiva } \\
\text { Campos }\end{array}$ & $\begin{array}{l}\text { Rubens } \\
\text { Eugenio } \\
\text { Barreto } \\
\text { Ramos }\end{array}$ & UFRN & $X$ & & M60 \\
\hline 2008 & Doutor & $\begin{array}{l}\text { Avaliação institucional: o } \\
\text { uso dos resultados como } \\
\text { estratégia de } \\
\text { (re)organização dos } \\
\text { espaços de discussão } \\
\text { da universidade }\end{array}$ & $\begin{array}{l}\text { Elizeth } \\
\text { Gonzaga dos } \\
\text { Santos Lima }\end{array}$ & $\begin{array}{l}\text { Mara Regina } \\
\text { Lemes de } \\
\text { Sordi }\end{array}$ & Unicamp & $X$ & & D21 \\
\hline 2008 & Mestre & $\begin{array}{l}\text { Políticas de Avaliação } \\
\text { Institucional da } \\
\text { Educação Superior: o } \\
\text { caso da Universidade } \\
\text { Federal do Pará }\end{array}$ & $\begin{array}{l}\text { Maria Edilene } \\
\text { da Silva } \\
\text { Ribeiro }\end{array}$ & $\begin{array}{l}\text { Vera Lúcia } \\
\text { Jacob } \\
\text { Chaves }\end{array}$ & UFPA & $X$ & & M61 \\
\hline 2008 & Mestre & $\begin{array}{l}\text { Política pública de } \\
\text { avaliação da educação } \\
\text { superior - o SINAES na } \\
\text { universidade pública } \\
\text { estadual: o caso da } \\
\text { Universidade do Estado } \\
\text { da Bahia - Uneb }\end{array}$ & $\begin{array}{l}\text { Regina Lúcia } \\
\text { Bastos Vieira }\end{array}$ & $\begin{array}{l}\text { Katia } \\
\text { Siqueira de } \\
\text { Freitas }\end{array}$ & $\begin{array}{l}\text { Univ. } \\
\text { Católica de } \\
\text { Salvador }\end{array}$ & $X$ & & M62 \\
\hline 2008 & Mestre & $\begin{array}{l}\text { Eu avalio, tu avalias, nós } \\
\text { nos avaliamos?: a } \\
\text { experiência da Unidade } \\
\text { Universitária de Ciências } \\
\text { Sócio-Econômicas e } \\
\text { Humanas - } \\
\text { UnUCSEH/UEG com a } \\
\text { autoavaliação proposta } \\
\text { pelo SINAES }\end{array}$ & $\begin{array}{l}\text { Kelli } \\
\text { Consuêlo } \\
\text { Almeida de } \\
\text { Lima Queiroz }\end{array}$ & $\begin{array}{l}\text { José Vieira } \\
\text { de Sousa }\end{array}$ & UnB & $X$ & & M63 \\
\hline 2008 & Doutor & $\begin{array}{l}\text { Implicações do Exame } \\
\text { Nacional de } \\
\text { Desempenho dos } \\
\text { Estudantes (ENADE) } \\
\text { nos processos } \\
\text { avaliativos internos do } \\
\text { curso de Educação } \\
\text { Física do IPA }\end{array}$ & $\begin{array}{l}\text { Denise } \\
\text { Grosso da } \\
\text { Fonseca }\end{array}$ & $\begin{array}{l}\text { Mari } \\
\text { Margarete } \\
\text { dos S. } \\
\text { Forster }\end{array}$ & $\begin{array}{l}\text { Univ. do } \\
\text { Vale do Rio } \\
\text { dos Sinos }\end{array}$ & $X$ & & D22 \\
\hline 2008 & Mestre & $\begin{array}{l}\text { ENADE: contribuições, } \\
\text { avanços e limites do } \\
\text { processo de avaliação } \\
\text { dos estudantes de } \\
\text { graduação }\end{array}$ & $\begin{array}{l}\text { Viviane } \\
\text { Aparecida } \\
\text { Rodrigues }\end{array}$ & $\begin{array}{l}\text { Maria do } \\
\text { Carmo de } \\
\text { Lacerda } \\
\text { Peixoto }\end{array}$ & UFMG & $X$ & & M64 \\
\hline 2007 & Doutor & $\begin{array}{l}\text { Avaliação da educação } \\
\text { superior: uma realidade } \\
\text { na educação médica }\end{array}$ & $\begin{array}{l}\text { Gianna Lepre } \\
\text { Perim }\end{array}$ & $\begin{array}{l}\text { José Dias } \\
\text { Sobrinho }\end{array}$ & Unicamp & $X$ & & $\mathrm{D} 23$ \\
\hline 2007 & Doutor & $\begin{array}{l}\text { Gestão universitária em } \\
\text { instituições particulares: } \\
\text { os documentos } \\
\text { institucionais como } \\
\text { indicadores do modelo } \\
\text { de gestão }\end{array}$ & $\begin{array}{l}\text { José Carlos } \\
\text { Victorino de } \\
\text { Souza }\end{array}$ & $\begin{array}{l}\text { Marcos } \\
\text { Tarciso } \\
\text { Masetto }\end{array}$ & PUC SP & $X$ & & D24 \\
\hline
\end{tabular}




\begin{tabular}{|c|c|c|c|c|c|c|c|c|}
\hline Ano & Grau & Título & Autor & Orientador & IES & BDTD & $\begin{array}{l}\text { Banco } \\
\text { Capes }\end{array}$ & Código \\
\hline 2007 & Mestre & $\begin{array}{l}\text { A autoavaliação } \\
\text { institucional na visão dos } \\
\text { coordenadores das } \\
\text { comissões próprias de } \\
\text { avaliação das } \\
\text { instituições de ensino } \\
\text { superior de Campinas }\end{array}$ & $\begin{array}{l}\text { Rosana } \\
\text { Augusto }\end{array}$ & $\begin{array}{l}\text { Newton } \\
\text { Cesar } \\
\text { Balzan }\end{array}$ & $\begin{array}{c}\text { PUC } \\
\text { Campinas }\end{array}$ & $\bar{X}$ & & M65 \\
\hline 2007 & Mestre & $\begin{array}{l}\text { Participação, reflexão } \\
\text { crítica e movimento no } \\
\text { processo avaliativo do } \\
\text { SINAES: entrevistas } \\
\text { com membros de } \\
\text { comissões próprias de } \\
\text { avaliação sobre a } \\
\text { autoavaliação } \\
\text { institucional }\end{array}$ & $\begin{array}{l}\text { Raquel de } \\
\text { Godoy Retz }\end{array}$ & $\begin{array}{l}\text { Antonio } \\
\text { Carlos } \\
\text { Caruso } \\
\text { Ronca }\end{array}$ & PUC SP & $X$ & & M66 \\
\hline 2007 & Mestre & $\begin{array}{l}\text { Autoavaliação } \\
\text { institucional no ensino } \\
\text { superior: uma análise } \\
\text { comparativa do processo } \\
\text { realizado em uma } \\
\text { instituição pública e em } \\
\text { uma instituição privada }\end{array}$ & $\begin{array}{l}\text { Tereza } \\
\text { Cristina Dias }\end{array}$ & $\begin{array}{l}\text { José } \\
\text { Roberto } \\
\text { Reis }\end{array}$ & $\begin{array}{l}\text { Univ. } \\
\text { Federal de } \\
\text { Viçosa }\end{array}$ & $\mathrm{X}$ & & M67 \\
\hline 2007 & Mestre & $\begin{array}{l}\text { Autoavaliação da } \\
\text { Universidade Federal do } \\
\text { Ceará (com a palavra os } \\
\text { estudantes de pós- } \\
\text { graduação) }\end{array}$ & $\begin{array}{l}\text { Igor Lima } \\
\text { Rodrigues }\end{array}$ & $\begin{array}{l}\text { Wagner } \\
\text { Bandeira } \\
\text { Andriola }\end{array}$ & UFC & $X$ & & M68 \\
\hline 2007 & Mestre & $\begin{array}{l}\text { Avaliação dos processos } \\
\text { de comunicação e } \\
\text { informação com base na } \\
\text { gestão da informação e } \\
\text { inteligência competitiva: } \\
\text { um estudo de caso da } \\
\text { União Social Camiliana }\end{array}$ & $\begin{array}{l}\text { Antônio } \\
\text { Márcio } \\
\text { Mendonça do } \\
\text { Carmo }\end{array}$ & $\begin{array}{l}\text { Orandi Mina } \\
\text { Falsarella }\end{array}$ & $\begin{array}{c}\text { PUC } \\
\text { Campinas }\end{array}$ & & & M69 \\
\hline 2007 & Mestre & $\begin{array}{l}\text { Avaliação de cursos na } \\
\text { Universidade de Santa } \\
\text { Cruz do Sul e a } \\
\text { qualificação da } \\
\text { graduação: contribuições } \\
\text { e influências do olhar } \\
\text { externo da avaliação }\end{array}$ & $\begin{array}{l}\text { Ceres Eli } \\
\text { Vargas } \\
\text { Scheffer }\end{array}$ & $\begin{array}{l}\text { Marília } \\
\text { Costa } \\
\text { Morosini }\end{array}$ & PUC RS & $X$ & & M70 \\
\hline 2007 & Mestre & $\begin{array}{l}\text { Avaliação de proficiência } \\
\text { no ensino médico e de } \\
\text { enfermagem: Exame } \\
\text { Nacional de Cursos } \\
\text { (Provão) versus Exame } \\
\text { Nacional de } \\
\text { Desempenho dos } \\
\text { Estudantes (ENAD) }\end{array}$ & $\begin{array}{l}\text { Francisco de } \\
\text { Assis Batista } \\
\text { da Silva }\end{array}$ & & $\begin{array}{l}\text { Univ. } \\
\text { Católica de } \\
\text { Brasília }\end{array}$ & $X$ & & M71 \\
\hline 2006 & Mestre & $\begin{array}{l}\text { O processo de auto- } \\
\text { avaliação institucional do } \\
\text { sistema nacional de } \\
\text { avaliação da educação } \\
\text { superior - SINAES como } \\
\text { ferramenta de gestão } \\
\text { estratégica nas IES: um } \\
\text { estudo de caso }\end{array}$ & $\begin{array}{l}\text { Jorge } \\
\text { Henrique } \\
\text { Mariano } \\
\text { Cavalcante }\end{array}$ & & $\begin{array}{l}\text { Fund. } \\
\text { Getúlio } \\
\text { Vargas }\end{array}$ & $X$ & & M72 \\
\hline 2006 & Mestre & $\begin{array}{l}\text { Sistema de avaliação } \\
\text { institucional da } \\
\text { Faculdade São } \\
\text { Francisco de Assis: uma } \\
\text { abordagem com base no } \\
\text { Sistema Nacional de } \\
\text { Avaliação da Educação } \\
\text { Superior - SINAES: Lei } \\
\text { 10.861/04 }\end{array}$ & $\begin{array}{l}\text { Otávio Borsa } \\
\text { Antonello }\end{array}$ & $\begin{array}{l}\text { Paulo } \\
\text { Schmidt }\end{array}$ & UFRGS & $X$ & & M73 \\
\hline
\end{tabular}




\begin{tabular}{|c|c|c|c|c|c|c|c|c|}
\hline Ano & Grau & Título & Autor & Orientador & IES & BDTD & $\begin{array}{l}\text { Banco } \\
\text { Capes }\end{array}$ & Código \\
\hline 2006 & Mestre & $\begin{array}{l}\text { Políticas de avaliação } \\
\text { para a educação } \\
\text { superior: um estudo } \\
\text { analítico sobre as } \\
\text { práticas discursivas nos } \\
\text { governos de Fernando } \\
\text { Henrique Cardoso e Luiz } \\
\text { Inácio Lula da Silva }\end{array}$ & $\begin{array}{l}\text { Bruna } \\
\text { Tarcília } \\
\text { Ferraz }\end{array}$ & $\begin{array}{l}\text { Alfredo } \\
\text { Macedo } \\
\text { Gomes }\end{array}$ & UFPE & $X$ & & M74 \\
\hline 2005 & Mestre & $\begin{array}{l}\text { A autoavaliação das } \\
\text { instituições de educação } \\
\text { superior catarinenses } \\
\text { diante da consolidação } \\
\text { do sistema nacional de } \\
\text { avaliação da educação } \\
\text { superior (SINAES) }\end{array}$ & $\begin{array}{l}\text { Marcelo } \\
\text { Recktenvald }\end{array}$ & $\begin{array}{l}\text { Amélia } \\
\text { Silveira }\end{array}$ & $\begin{array}{l}\text { Univ. } \\
\text { Regional } \\
\text { de } \\
\text { Blumenau }\end{array}$ & 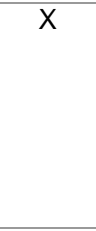 & & M75 \\
\hline 2005 & Mestre & $\begin{array}{l}\text { A adaptação estratégica } \\
\text { dos programas de } \\
\text { avaliação institucional } \\
\text { implementados no } \\
\text { ensino superior brasileiro } \\
\text { a partir da década de } \\
1980\end{array}$ & $\begin{array}{l}\text { Renata } \\
\text { Cavallazzi } \\
\text { Zimmer }\end{array}$ & $\begin{array}{l}\text { Jovane } \\
\text { Medina } \\
\text { Azevedo }\end{array}$ & $\begin{array}{l}\text { Univ. do } \\
\text { Estado de } \\
\text { Santa } \\
\text { Caterina }\end{array}$ & $x$ & & M76 \\
\hline 2004 & Mestre & $\begin{array}{l}\text { Avaliação do ensino } \\
\text { superior brasileiro: } \\
\text { PAIUB, ENC e o } \\
\text { SINAES }\end{array}$ & $\begin{array}{l}\text { Rogério } \\
\text { Evaristo } \\
\text { Versieux }\end{array}$ & $\begin{array}{l}\text { Luis Carlos } \\
\text { de Freitas }\end{array}$ & Unicamp & X & & M77 \\
\hline
\end{tabular}

Ao longo do período pesquisado - 2004 a 2014 - a concentração maior desses trabalhos está entre os anos de 2011 a 2014, sendo o ano de 2012, notadamente, o com a maior quantidade de obras. O Gráfico 1 ilustra esse cenário.

\section{Gráfico 1 - Teses e dissertações sobre o SINAES no período 2004 - 2014}

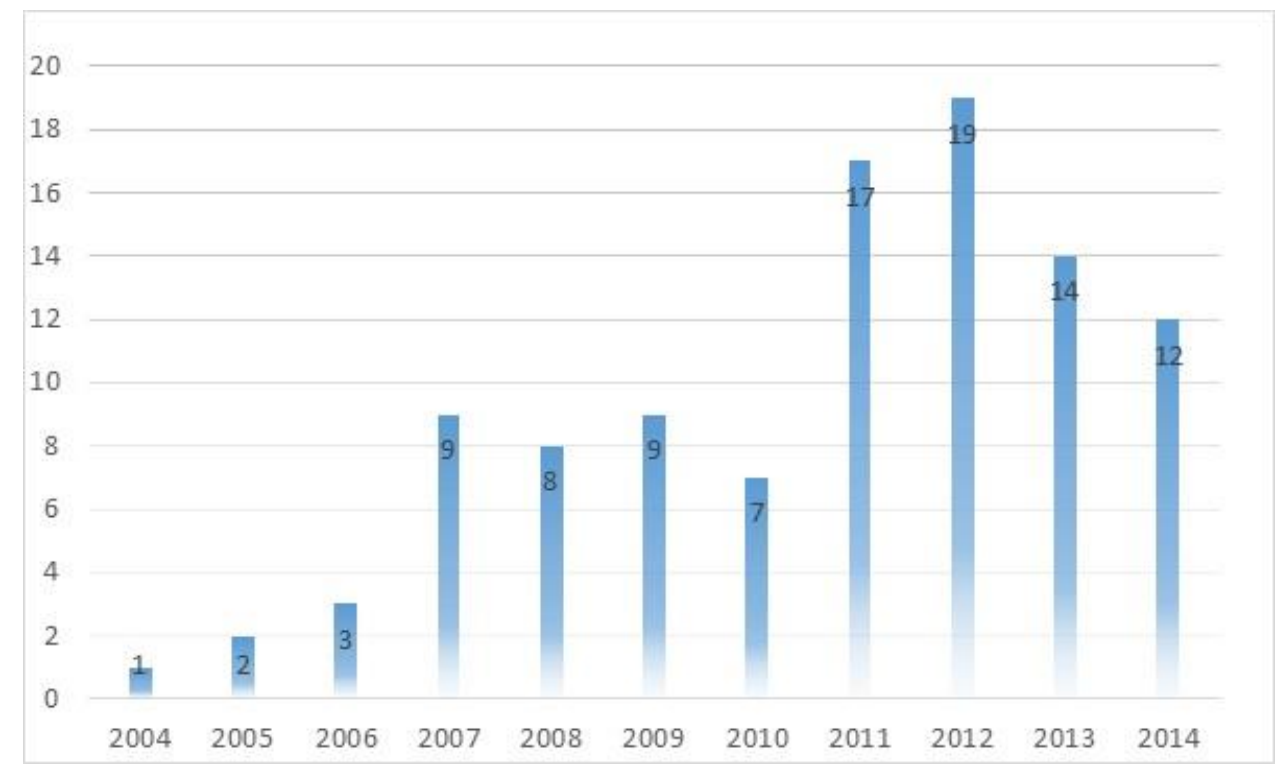

O SINAES foi instituído em 2004, portanto, é compreensível que o número de publicações sobre essa política pública aumente a partir de 3 ou 4 anos depois, conforme os alunos-pesquisadores defendem suas dissertações e teses. A única obra sobre o SINAES em 
2004, por exemplo, ainda faz referências sobre os estudos preliminares da Comissão Especial de Avaliação (CEA), ou seja, o SINAES ainda era um projeto em processo de concepção.

É notório o aumento expressivo de obras a partir de 2011, sendo possível dividir essa linha do tempo em dois períodos: (i) período 2004 - 2010 e (ii) período 2011 - 2014. Não temos elementos consistentes neste estudo para explicar tal fato, porém, poderíamos hipotetizar se isto não se deve ao fato de o SINAES ter passado por modificações significativas a partir de 2006, havendo alguns autores, inclusive, que classificam o SINAES em 2 momentos: $1^{\circ}$ governo Lula e $2^{\circ}$ governo Lula. (BARREYRO; ROTHEN, 2014, 2011). Essas modificações dizem respeito, sobremaneira, à criação de índices a partir de 2007, sobre os quais as instituições e cursos passaram a ser ranqueados, o que provocou uma mudança substancial no projeto original da avaliação. Tal "desvirtuamento" do SINAES (DIAS SOBRINHO, 2008; ROTHEN; BARREYRO, 2011) talvez tenha despertado a curiosidade de pesquisadores cujas obras foram concluídas a partir de 2011.

As pesquisas são oriundas de todo o país, de todas as regiões, das mais diversas universidades. A Tabela 2 mostra-nos a distribuição das obras por cada instituição.

Tabela 2 - Teses e dissertações sobre o SINAES por IES

\begin{tabular}{|c|c|}
\hline INSTITUIÇÃO & QUANTIDADE \\
\hline Universidade de Brasília (UnB) & 13 \\
\hline Universidade Federal do Ceará (UFC) & 11 \\
\hline Pontifícia Universidade Católica de São Paulo (PUC SP) & 7 \\
\hline Universidade Federal da Bahia (UFBA) & 6 \\
\hline Universidade Estadual de Campinas (Unicamp) & 6 \\
\hline Universidade Federal de Pernambuco (UFPE) & 3 \\
\hline Universidade Federal do Rio Grande do Norte (UFRN) & 4 \\
\hline Universidade Estadual Paulista (Unesp) & 2 \\
\hline Universidade Federal do Rio Grande do Sul (UFRGS) & 3 \\
\hline Fundação Cesgranrio & 3 \\
\hline Universidade Federal da Paraíba (UFPB) & 3 \\
\hline Pontifícia Universidade Católica de Campinas (PUC Campinas) & 3 \\
\hline Universidade Federal de Santa Maria (UFSM) & 3 \\
\hline Universidade Federal de São Carlos (UFSCar) & 2 \\
\hline Universidade Federal do Pará (UFPA) & 2 \\
\hline Universidade Federal de Uberlândia (UFU) & 2 \\
\hline Universidade Católica de Santos (Unisantos) & 2 \\
\hline Universidade de São Paulo (USP) & 2 \\
\hline Universidade Federal do Amazonas (UFAM) & 2 \\
\hline Fundação Getúlio Vargas (FGV) & 1 \\
\hline Universidade Federal de Santa Catarina (UFSC) & 1 \\
\hline Universidade Federal de Juiz de Fora (UFJF) & 1 \\
\hline Universidade Cândido Mendes & 1 \\
\hline Universidade Federal de Rondônia (UFRO) & 1 \\
\hline Universidade Positivo & 1 \\
\hline Faculdade Tecnologia SENAI CIMATEC & 1 \\
\hline
\end{tabular}




\begin{tabular}{l|c} 
Universidade Cidade de São Paulo (UNICID) & 1 \\
\hline Universidade Federal da Grande Dourados (UFGD) & 1 \\
\hline Universidade Federal de Alagoas (UFAL) & 1 \\
\hline Universidade Católica de Brasília (UCB) & 1 \\
\hline Universidade do Vale do Rio dos Sinos (Unisinos) & 1 \\
\hline Pontifícia Universidade Católica do Rio Grande do Sul (PUC RS) & 1 \\
\hline Universidade Estadual do Oeste do Paraná (Unioeste) & 1 \\
\hline Universidade do Estado de Santa Catarina (UDESC) & 1 \\
\hline Universidade Federal de Viçosa (UFV) & 1 \\
\hline Universidade Católica de Salvador (UCSAL) & 1 \\
\hline Universidade Regional de Blumenau (FURB) & 1 \\
\hline Universidade Tuiuti do Paraná & 1 \\
\hline Universidade Federal de Minas Gerais (UFMG) & 1 \\
\hline Universidade Metodista de São Paulo & 1 \\
\hline Universidade do Estado do Rio de Janeiro (UERJ) & 1 \\
\hline
\end{tabular}

Universidade de Brasília (UnB) e Universidade Federal do Ceará (UFC) são as instituições com o maior número de produções sobre o SINAES, seguidas por PUC São Paulo, Universidade Federal da Bahia e Unicamp.

A Tabela 3 nos permite visualizar a relação de professores que orientaram dois ou mais trabalhos e suas respectivas instituições de origem. Os demais orientadores não listados nesta tabela orientaram somente uma pesquisa.

Tabela 3 - Orientadores das teses e dissertações sobre o SINAES e as IES de origem

\begin{tabular}{lcl}
\hline \multicolumn{1}{c}{ Orientadores } & Instituição & Quantidade \\
\hline José Vieira de Souza & UnB & 9 \\
\hline Wagner Andriola & UFC & 6 \\
\hline Alfredo Macedo Gomes & UFPE & 3 \\
\hline Robert Evan Verhine & UFBA & 3 \\
\hline Alberto Souza Schmidt & UFSM & 3 \\
\hline Marília Fonseca & UnB & 3 \\
\hline Maria Angelica Rodrigues Martins & Unisantos & 2 \\
\hline Angela Carrancho da Silva & Fund. Cesgranrio & 2 \\
\hline Robinson Moreira Tenório & UFBA & 2 \\
\hline
\end{tabular}

Do universo de 101 trabalhos, praticamente um terço (33 obras) foram orientados por nove professores. As demais pesquisas (68), foram orientadas por 68 professores, ou seja, uma pesquisa para cada orientador.

E como a Tabela 3 nos mostra, dentre os nove orientadores mais profícuos, há uma sensível concentração em José Vieira de Souza, da Universidade de Brasília (UnB) e Wagner 
Bandeira Andriola, da Univrsidade Federal do Ceará (UFC). Ambas as instituições, por conta desses pesquisadores, são as mais profícuas na produção de pesquisas sobre o SINAES.

Importante destacar, por fim, que na UFC todos os trabalhos são de mestrado e Wagner Bandeira Andriola é o único professor dessa IES com mais de dois trabalhos sob sua orientação. $\mathrm{Na}$ UnB, tanto há trabalhos de mestrado como de doutorado, e além de José Vieira de Souza, há também um outro professor que orientou mais de dois trabalhos: Marília Fonseca.

Na Figura 2 apresentamos a categorização dos trabalhos, identificando-os por meio dos códigos atribuídos na última coluna do Quadro 1. Lemos cada um dos resumos a fim de identificar sobre qual dimensão do SINAES a obra se tratava. A pergunta que tentávamos responder nessa primeira etapa da categorização era: esta obra é sobre (i) avaliação da instituição ou (ii) avaliação de curso ou (iii) avaliação de estudante?

\section{Figura 2 - Categorização das obras pelos eixos do SINAES}

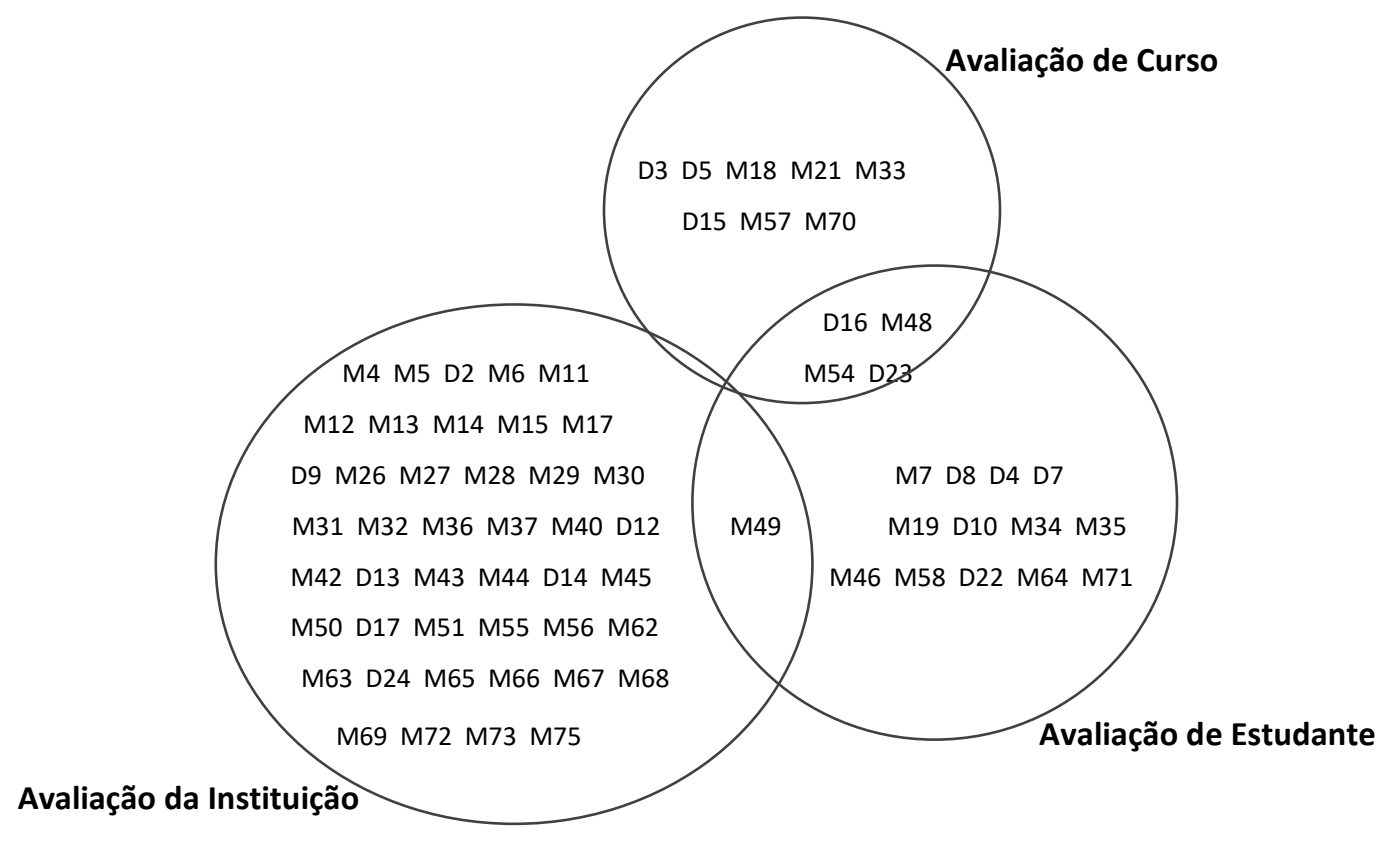

Como esperado, havia trabalhos facilmente identificáveis, bem como trabalhos que precisamos reservar para uma leitura mais acurada em um segundo momento. E havia também pesquisas que tratavam de dois aspectos do SINAES ao mesmo tempo. A Figura 2 nos mostra que a maior parte dos trabalhos está no eixo Avaliação Institucional, e que praticamente todos os trabalhos desse eixo tratam exclusivamente disso, não havendo interseção com os demais eixos (com exceção do trabalho M49). 
Além dos 78 trabalhos categorizados na Figura 2, há outros 28 que se distribuíram em outras categorias que não, propriamente, um ou outro eixo do SINAES. O Quadro 2 nos permite essa visualização geral, portanto, de todos os trabalhos e suas categorias.

Quadro 2 - Categorização das obras de mestrado e doutorado sobre o SINAES 2004 - 2014

\begin{tabular}{|c|c|c|c|c|c|}
\hline \multicolumn{3}{|c|}{ ESTRUTURA DO SINAES } & \multicolumn{3}{|c|}{ OUTRAS CATEGORIAS } \\
\hline \multicolumn{3}{|c|}{78 trabalhos } & \multicolumn{3}{|c|}{28 trabalhos } \\
\hline $\begin{array}{l}\text { Avaliação da } \\
\text { Instituição }\end{array}$ & $\begin{array}{l}\text { Avaliação do } \\
\text { curso }\end{array}$ & $\begin{array}{l}\text { Avaliação do } \\
\text { estudante }\end{array}$ & $\begin{array}{l}\text { Análise } \\
\text { histórica e/ou } \\
\text { teórica do } \\
\text { SINAES como } \\
\text { um todo }\end{array}$ & $\begin{array}{l}\text { Implementação } \\
\text { ou gestão do } \\
\text { SINAES como um } \\
\text { todo em uma IES } \\
\text { específica ou } \\
\text { grupo de IES }\end{array}$ & $\begin{array}{l}\text { Comparação /utilização } \\
\text { de alguma ferramenta } \\
\text { de gestão } \\
\text { organizacional com } \\
\text { o/no SINAES }\end{array}$ \\
\hline 47 trabalhos & 12 trabalhos & 18 trabalhos & 9 trabalhos & 13 trabalhos & 6 trabalhos \\
\hline $\begin{array}{l}\text { M4, M5, D2, M6, } \\
\text { M11, M12, M13, } \\
\text { M14, M15, M16, } \\
\text { M17, D9, M26, } \\
\text { M27, M28, M29, } \\
\text { M30, M31, M32, } \\
\text { M36, M37, M40, } \\
\text { D12, M42, D13, } \\
\text { M43, M44, D14, } \\
\text { M45, M49, M50, } \\
\text { D17, D18, M51, } \\
\text { M55, M56, M62, } \\
\text { M63, D24, M65, } \\
\text { M66, M67, M68, } \\
\text { M69, M72, M73, } \\
\text { M75 }\end{array}$ & $\begin{array}{l}\text { D3, D5, M18, } \\
\text { M21, M33, } \\
\text { D15, D16, } \\
\text { M48, M54, } \\
\text { M57, D23, M70 }\end{array}$ & $\begin{array}{l}\text { M7, D8, D4, D7, } \\
\text { M19, D10, M34, } \\
\text { M35, D16, M46, } \\
\text { M48, M49, M54, } \\
\text { M58, D22, M64, } \\
\text { D23, M71 }\end{array}$ & $\begin{array}{l}\text { M3, D6, M10, } \\
\text { M20, M25, } \\
\text { M39, D20, } \\
\text { M74, M76, M77 }\end{array}$ & $\begin{array}{l}\text { M2, D1, M22, } \\
\text { M23, M24, D8, } \\
\text { D11, M38, M41, } \\
\text { M47, D19, D21, } \\
\text { M61 }\end{array}$ & $\begin{array}{l}\text { M1, M9, M52, M53, } \\
\text { M59, M60 }\end{array}$ \\
\hline
\end{tabular}

\section{Considerações finais}

Esse estudo, uma espécie de inventário da produção de teses e dissertações sobre o SINAES no período 2004 a 2014, ainda que circunscrito a informações de caráter mais quantitativo do que qualitativo, nos permite uma visão panorâmica do que se produziu nos dez primeiros anos de vigência dessa política pública de avaliação.

Interessados no campo conseguem visualizar tendências temáticas - recorrências e faltas - bem como lugares e pessoas envolvidas com o assunto. Fizemos questão de apresentar, nominalmente, cada uma das obras (Quadro 1), de modo que o leitor pudesse, ele mesmo, questionar e repensar as categorias criadas por nós ou, até mesmo, ante disso, analisar a própria presença ou ausência de obras que, porventura, julgar apropriado ou inapropriado.

Além disso, uma vez que todas essas obras estão disponíveis integralmente nos sítios dos indexadores usados (Banco de Teses e Dissertações da Capes e BDTD), tal quadro pode contribuir com uma agenda de leituras - sobretudo de pesquisadores em formação (mestrandos e doutorandos) - para uma imersão no campo e estabelecimento de pontos de partida, seja pela 
convergência, seja pela divergência. Afinal, construção de conhecimento é esse movimento vivo e coletivo. E sempre inacabado.

\section{Referências}

BARREYRO, Gladys B. Do Provão ao SINAES: o processo de construção de um novo modelo de avaliação da educação superior. Avaliação, Campinas; Sorocaba, v. 9, n. 1, p.3749, março 2004.

BARREYRO, Gladys B.; ROTHEN, José C. "SINAES" contraditórios: considerações sobre a elaboração e implantação do sistema nacional de avaliação da educação superior. Educação \& Sociedade, Campinas, v. 27, n. 96, p. 955-977, 2006.

BARREYRO, Gladys B.; ROTHEN, José C. Percurso da avaliação da educação superior nos Governos Lula. Educ. Pesqui., São Paulo, v. 40, n. 1, p. 61-76, jan./mar. 2014.

DIAS SOBRINHO, José. Qualidade, avaliação: do SINAES a índices. Avaliação, Campinas; Sorocaba, SP, v. 13, n. 3, p. 817-825, nov. 2008.

FERNANDES, Reynaldo et al. Avaliação de cursos na educação superior: a função e a mecânica do conceito preliminar de curso. Serie Documental, Brasília, n. 32, p. 5-18, 2009.

POLIDORI, Marlis Morosini; MARINHO-ARAUJO, Claisy M.; BARREYRO. SINAES: perspectivas e desafios na avaliação da educação superior brasileira. Ensaio: aval. pol. públ. Educação, Rio de Janeiro, v. 14, n. 53, p.425-436, out./dez., 2006.

ROTHEN, José Carlos; BARREYRO, Gladys Beatriz. Avaliação da educação superior no segundo governo Lula: "Provão II" ou a reedição de velhas práticas? Educação \& Sociedade, Campinas, v. 32, n. 114, p. 21-38, jan./mar., 2011.

Paulo Roberto Teixeira Junior - Faculdade de Engenharia de Sorocaba Sorocaba | SP | Brasil. Contato: paulo.teixeira@facens.br

Monica Piccione Gomes Rios - Pontifícia Universidade Católica de Campinas Campinas | SP | Brasil. Contato: monica.rios@ @uccampinas.edu.br 